Chapter 20

\title{
Analysis of Meiotic Recombination Products From Human Sperm
}

Liisa Kauppi*, Celia A. May and Alec J. Jeffreys

*corresponding author

Running Title: Meiotic Recombination in Human Sperm 


\section{Abstract}

Traditional methods for surveying meiotic recombination in humans are limited to pedigree and linkage disequilibrium analyses. We have developed assays that allow the direct detection of crossover and gene conversion molecules in batches of sperm DNA. To date, we have characterized 26 recombination hotspots by allele-specific PCR and selectively amplified recombinant DNA molecules from these regions. These analyses have revealed that meiotic crossover hotspots in humans are highly localized and flanked by DNA segments where recombination is suppressed. The centers of crossover hotspots are also active in non-crossover recombination, displaying short conversion tracts.

Key Words: allele-specific PCR, haplotype, sperm DNA, crossover, gene conversion

\section{Introduction}

Human DNA diversity arises from germline mutation, creating new haplotypes that are then reshuffled by meiotic recombination. It has become increasingly obvious that meiotic recombination events in mammals are not randomly distributed, but instead cluster into highly localized regions (recombination hotspots).

Several experimental approaches have been used to characterize the frequency and spatial distribution of meiotic recombination events in humans. Examining parent-to-offspring transmission of alleles at several loci (the so-called pedigree approach) has identified localized genomic regions, at the $1-10 \mathrm{~kb}$ scale, in which recombination events appear to cluster (for example, refs. 1-5). However, because of the small size of human families, the number of 
informative meioses is limited. This approach to measuring meiotic recombination rates thus is not suitable for detecting low frequency events or for defining hotspots with precision.

An alternative method for elucidating the genome-wide distribution of recombination events is to examine patterns of linkage disequilibrium (LD). LD reflects recombination in all of the generations since the rise of the individual polymorphic alleles under study. Various LD measures exist for characterizing the statistical association between alleles at different loci (see, e.g., refs. 6, 7 for reviews). High-resolution LD analyses of the human genome show extended domains of markers in strong association interrupted by areas of $\operatorname{LD}$ breakdown $(\boldsymbol{8}, \mathbf{9})$.

In principle, if strong LD is found between two loci, little if any historical recombination has occurred between the loci. Conversely, little or no LD (that is, breakdown of LD) implies historical recombination activity. Regions of LD breakdown are therefore putative recombination hotspots, and can be directly tested for crossover and gene conversion activity, as we describe in this chapter. However, patterns of LD can be influenced also by the age of crossover events, selection acting on single or linked alleles, and demographic history $(10,11)$, highlighting the importance of experimentally verifying recombination activity in a region of interest.

In this chapter, we describe strategies to identify and characterize human recombination hotspots. First, high-resolution LD structure is examined to identify signatures of historical crossing-over (Fig. 1A). LD profiles can sometimes be complex, so genotype data can also be analyzed by linkage disequilibrium unit mapping to provide a simple summary profile of the rate of LD breakdown across the genotyped region, facilitating the detection of putative hotspots (12). More sophisticated coalescent methods are also available that allow detailed estimation of the historical recombination profile across the region most compatible with contemporary haplotype diversity (13-16). The next step is to test LD block boundaries (putative hotspots) for 
meiotic recombination hotspot activity using allele-specific PCR to recover crossover molecules directly from sperm DNA (Fig. 1B). Crossover breakpoint mapping and the resolution of hotspots is limited only by the density of heterozygous markers within the target region; resolution to less than $0.5 \mathrm{~kb}$ is usually possible by choosing individuals with appropriate genotypes. Once the precise location of a crossover hotspot is known, assays can be designed to analyze non-crossover recombination events (gene conversions) at the center of the hotspot.

Sperm typing experiments have demonstrated that areas of LD breakdown frequently correspond with generally good precision to meiotic crossover hotspots $(15,17-21)$. All hotspots defined share similar widths (1-2 kb wide) but vary considerably in intensity with sperm recombination frequencies varying from $0.0004 \%$ to $1 \%$ over currently characterized hotspots. Crossover hotspots often occur in clusters and together account for at least $80 \%(13,16,22)$, and probably more than $95 \%(\mathbf{1 5}, \mathbf{2 3})$, of all crossovers in the male germline.

To facilitate the analysis of non-crossover gene conversions at hotspots, a DNA enrichment-based assay has been developed that can capture conversion events involving even single SNP sites (24). Assays performed at three human crossover hotspots showed that conversions are even more localized, although they peak in activity at the centre of the crossover hotspot (25). This is consistent with crossovers and conversions being produced by the same initiation events, presumably DNA double-strand breaks. Conversion tracts are very short $(<300$ bp on average), and initiation events seem to cluster within a zone of just $\sim 400 \mathrm{bp}$. However, data from five loci indicate that the relative frequencies of conversion to crossover show major variation between hotspots, ranging from $\sim 10: 1$ to $<1: 12(25-27)$.

The methods described in this chapter have provided significant insight into the nature of human meiotic recombination. The obvious drawback of sperm PCR techniques is that they can 
only be used to analyze meiotic recombination in human males. Pedigree data remain essential for analyzing the distribution and rate of female recombination events, though population genetic inferences of historical recombination in females can be gained by LD analysis of the sexspecific region of the $\mathrm{X}$ chromosome.

\section{Materials}

To minimize the risk of contamination with environmental DNA, all reagents should be prepared in a laminar flow hood using dedicated pipettes plus plasticware taken directly from the manufacturers' bags/boxes. Buffers can be further treated by exposure to UV light to eliminate any possible PCR-amplifiable DNA.

\subsection{DNA extractions}

1. 20x sodium chloride-sodium citrate (SSC) buffer: $3 \mathrm{M} \mathrm{NaCl}, 0.3 \mathrm{M}$ sodium citratedihydrate; use to make 1x SSC and $0.2 \mathrm{x} \mathrm{SSC}$ in $\mathrm{ddH}_{2} \mathrm{O}$

2. $10 \%(\mathrm{w} / \mathrm{v})$ sodium dodecyl sulfate (SDS)

3. 2-mercaptoethanol

4. $20 \mathrm{mg} / \mathrm{ml}$ Proteinase $\mathrm{K}$ in $\mathrm{ddH}_{2} \mathrm{O}$; prepare fresh, store on ice until use

5. Liquefied phenol, washed in Tris buffer (general purpose grade)

6. $2 \mathrm{M}$ sodium acetate $\mathrm{pH} 7.0$

7. Ethanol, absolute and $80 \%$

8. $\quad 5 \mathrm{mM}$ Tris- $\mathrm{HCl} \mathrm{pH} 7.5$

9. Screw-top $1.5 \mathrm{~mL}$ microcentrifuge tubes (Sarstedt, Nümbrecht, Germany) 


\subsection{Allele-specific PCR}

1. 11.1x PCR buffer, prepared as indicated in Table 1. Non-acetylated Ultrapure bovine serum albumin (BSA) is supplied by Ambion (Austin, TX). Freeze in $100 \mu \mathrm{L}$ aliquots and store at $-20^{\circ} \mathrm{C}$.

2. Taq polymerase (ABgene, Epsom, UK)

3. Pfu polymerase

4. $2 \mathrm{M}$ Tris(hydroxymethyl)aminomethane (Ultra grade for molecular biology, Fluka Chemie, Buchs, Switzerland) in $\mathrm{ddH}_{2} \mathrm{O}$

5. $\mathrm{S} 1$ nuclease, diluted in $\mathrm{S} 1$ nuclease storage buffer $(20 \mathrm{mM}$ Tris- $\mathrm{HCl} \mathrm{pH} 7.5,50 \mathrm{mM}$ $\mathrm{NaCl}, 0.1 \mathrm{mM}$ zinc acetate, $50 \%$ [v/v] glycerol). Store at a concentration of $10 \mathrm{U} / \mu \mathrm{L}$ at $20^{\circ} \mathrm{C}$. Stable for $>6$ months.

6. S1 digestion buffer: $20 \mathrm{mM}$ sodium acetate $\mathrm{pH} 4.9,1 \mathrm{mM}$ zinc acetate, $100 \mathrm{mM} \mathrm{NaCl}$. Store at $-20^{\circ} \mathrm{C}$.

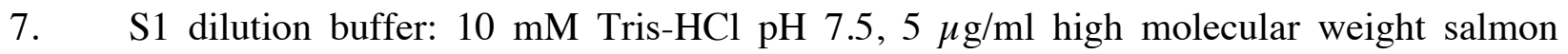
sperm DNA

8. 10x Tris-borate/EDTA (TBE) buffer: $890 \mathrm{mM}$ Tris-Borate, $20 \mathrm{mM}$ EDTA in $\mathrm{ddH}_{2} \mathrm{O}, \mathrm{pH}$ 8; use to make $0.5 \mathrm{x}$ TBE in $\mathrm{ddH}_{2} \mathrm{O}$. Store at room temperature.

9. All-purpose loading dye: $30 \%$ (v/v) glycerol in 0.5x TBE plus enough bromophenol blue to give adequate blue color. Store at room temperature.

10. Seakem LE agarose

11. Ethidium bromide 


\subsection{Mapping crossover breakpoints by allele-specific oligonucleotide (ASO) hybridization}

1. Denaturing solution: $0.5 \mathrm{M} \mathrm{NaOH}, 2 \mathrm{M} \mathrm{NaCl}, 25 \mathrm{mM}$ EDTA. Store at room temperature.

2. $2 x$ SSC and $3 x$ SSC

3. Hybond membrane (Amersham) and 3MM Whatman filter paper

4. Allele-specific oligonucleotides (ASOs), desalted, 18 nucleotides long, with SNP site located at the eighth base from $5^{\prime}$ end. Store at $800 \mu \mathrm{g} / \mathrm{ml}$ concentration in $\mathrm{ddH}_{2} \mathrm{O}$ at $20^{\circ} \mathrm{C}$. Dilute $1: 100$ in $\mathrm{ddH}_{2} \mathrm{O}$ to make working stock of $8 \mu \mathrm{g} / \mathrm{ml}$.

5. T4 polynucleotide kinase

6. T4 kinase labeling mix: $700 \mathrm{mM}$ Tris- $\mathrm{HCl} \mathrm{pH} \mathrm{7.5,} 100 \mathrm{mM} \mathrm{MgCl}, 50 \mathrm{mM}$ spermidine trichloride (Sigma), $20 \mathrm{mM}$ dithiothreitol. Store at $-20^{\circ} \mathrm{C}$.

7. $10 \mathrm{mCi} / \mathrm{ml}\left[\gamma^{32}{ }^{32} \mathrm{P}\right] \mathrm{ATP}$

8. T4 kinase stop mix: $25 \mathrm{mM}$ di-sodium EDTA, $0.1 \% \mathrm{SDS}, 10 \mu \mathrm{M}$ ATP. Store at $-20^{\circ} \mathrm{C}$.

9. 50x Denhardt's solution: $5 \mathrm{~g}$ Ficoll400, $5 \mathrm{~g}$ polyvinylpyrrolidone, $5 \mathrm{~g}$ BSA fraction V, dissolved in $500 \mathrm{~mL} \mathrm{ddH_{2 }} \mathrm{O}$. Store at $+4^{\circ} \mathrm{C}$.

10. High-molecular weight salmon testis DNA or herring sperm DNA, $3 \mathrm{mg} / \mathrm{ml}$ in $\mathrm{ddH}_{2} \mathrm{O}$

11. Tetramethyl-ammonium chloride (TMAC) hybridization solution: $3 \mathrm{M}$ TMAC, $0.6 \%$ SDS, $10 \mathrm{mM}$ sodium phosphate $\mathrm{pH}$ 6.8, $1 \mathrm{mM}$ EDTA, $4 \mu \mathrm{g} / \mathrm{ml}$ yeast (bulk) RNA, in 5x Denhardt's solution. Store at $+4^{\circ} \mathrm{C}$.

12. TMAC wash solution: $3 \mathrm{M}$ TMAC, $0.6 \%$ SDS, $10 \mathrm{mM}$ sodium phosphate $\mathrm{pH} 6.8,1 \mathrm{mM}$ EDTA. Store at $+4^{\circ} \mathrm{C}$.

13. Rotator hybridization oven (e.g. Thermo Hybaid)

14. Pyrex or plastic tray 
15. Saran plastic wrap

16. Autoradiography film

17. Stripping solution: $0.1 \% \mathrm{SDS}$ in $\mathrm{ddH}_{2} \mathrm{O}$

\subsection{DNA enrichment by allele-specific hybridization (DEASH)}

1. Restriction enzyme and buffer (see Section 3.5.1)

2. $\quad 0.1 \mathrm{M}$ spermidine trichloride

3. $2 \mathrm{M}$ sodium acetate $\mathrm{pH} 7.0$

4. Ethanol, absolute and $80 \%$

5. $\quad 5 \mathrm{mM}$ Tris- $\mathrm{HCl} \mathrm{pH} 7.5$

6. 5 ' biotinylated ASO purified by HPLC; 18 nucleotides long with allele-specific base as the 11 th nucleotide from the $5^{\prime}$ end, store as $5 \mu \mathrm{M}(30 \mu \mathrm{g} / \mathrm{ml})$ working stock in $\mathrm{ddH}_{2} \mathrm{O}$

7. Non-biotinylated competitor ASO; corresponding $18 \mathrm{mer}$ with opposite allele base at $11 \mathrm{nt}$ from $5^{\prime}$ end, store as $30 \mu \mathrm{M}(180 \mu \mathrm{g} / \mathrm{ml})$ working stock

8. Dynabeads M-280 Streptavidin (store in the dark at $+4^{\circ} \mathrm{C}$ ) and Dynal MPC-E magnetic particle concentrator (Dynal Biotech, Invitrogen)

9. 10x DHB (denaturing/hybridizing/binding buffer); $450 \mathrm{mM}$ Tris- $\mathrm{HCl} \mathrm{pH} 8.8,110 \mathrm{mM}$ ammonium sulphate, $45 \mathrm{mM} \mathrm{MgCl}_{2}, 67 \mathrm{mM}$ 2-mercaptoethanol, $44 \mu \mathrm{M}$ disodium EDTA, $20 \mu \mathrm{g} / \mathrm{ml}$ single-stranded (heat-denatured) high molecular weight herring sperm or salmon testis DNA

10. $500 \mu \mathrm{g} / \mathrm{ml}$ non-acetylated Ultrapure BSA (Ambion)

11. $\mathrm{ED}$ (elution buffer): $0.14 \mathrm{x} \mathrm{DHB}, 4.7 \mu \mathrm{g} / \mathrm{ml}$ single-stranded (heat-denatured) high molecular weight herring or salmon sperm DNA 
12. $0.2 \mathrm{~mL}$ PCR tubes

13. Siliconized $1.5 \mathrm{~mL}$ flip-top microcentrifuge tubes, prepared by soaking open tubes in dimethyldichlorosilane solution (BDH, Lutterworth UK) for 1 minute, draining, leaving to air dry completely in a PCR-clean environment ( $\sim 10$ minutes), then washing thoroughly with $\mathrm{dH}_{2} \mathrm{O}$ and air drying again before storing in sealed bag at room temperature. Commercially available siliconized tubes appear to be less reliable and can cause reduced yields due to adsorption of single stranded DNA.

14. Two waterbaths, one set at temperature to anneal biotinylated ASO to target and other at temperature to elute the bound DNA

15. If Alu competitor is required, $10 \mu \mathrm{M}$ working stocks of primers Alu-F (5'

GGTGGCTCACGCCTGTAATC 3') and Alu-R (5' AGACGGAGTCTCGCTCTGTG 3')

\section{Methods}

\subsection{DNA extractions}

All DNA extractions should be carried out in a laminar flow hood under conditions that minimize risk of contamination (28). Waste material must be discarded into disinfectant (e.g. solution made with Titan Chlor-Tabs 500, Lever Industrial, Runcorn, Cheshire UK) to destroy any pathogens.

\subsubsection{Extracting DNA from semen}

1. Semen donors should be requested to wash the penis prior to ejaculation to minimize the risk of contamination with cellular material from their partner. Ejaculates should be 
collected in $5 \mathrm{~mL} 1 \mathrm{x}$ SSC and stored at $-80^{\circ} \mathrm{C}$. Samples so stored are suitable for sperm DNA preparation for at least 10 years.

2. Thaw sample and transfer $1 \mathrm{~mL}$ semen/SSC to a screw-top microfuge tube. For a typical ejaculate, this amount should yield $\sim 30 \mu \mathrm{g}$ sperm DNA. If larger amounts of DNA are required, then process multiple aliquots of semen in parallel. Centrifuge at 13,000 rpm $(15,700 \mathrm{~g})$ in a microcentrifuge for $2 \mathrm{~min}$, discard the supernatant and re-suspend the cell pellet in $1 \mathrm{~mL} 1 \mathrm{x}$ SSC with vigorous shaking until a uniform cell suspension is obtained. Add $20 \mu \mathrm{L} 10 \% \operatorname{SDS}(0.2 \%$ final concentration) to lyse any non-sperm cells. Mix contents by inverting vigorously and centrifuge at $13000 \mathrm{rpm}(15700 \mathrm{rcf})$ in a microcentrifuge for $2 \mathrm{~min}$. Discard the supernatant and re-suspend the pellet in $1 \mathrm{~mL} 1 \mathrm{x}$ SSC, $0.2 \%$ SDS. Centrifuge as before.

3. Discard the supernatant and re-suspend the pellet in $450 \mu \mathrm{L} 0.2 \mathrm{x}$ SSC. Lyse sperm heads by the addition of $50 \mu \mathrm{L} 10 \% \operatorname{SDS}$ (1\% final concentration), $35 \mu \mathrm{L}$ 2-mercaptoethanol (1 M final concentration) and Proteinase $\mathrm{K}$ to a final concentration of $200 \mu \mathrm{g} / \mathrm{mL}$. Mix by gently inverting the tube.

4. Incubate the sample for $30 \mathrm{~min}$ to $1 \mathrm{~h}$ in a waterbath at $37^{\circ} \mathrm{C}$ with occasional gentle mixing. Lysis should be evident within $5 \mathrm{~min}$ as the lysate becomes viscous. Spin in microcentrifuge at $13000 \mathrm{rpm}$ (15700 rcf) for $1 \mathrm{~min}$.

5. Remove any residual proteins by adding $350 \mu \mathrm{L}$ phenol, followed by gentle mixing by tube inversion to allow emulsification, and spin in a microcentrifuge at $13000 \mathrm{rpm}$ (15700 rcf) for $2 \mathrm{~min}$. Transfer the top aqueous layer into a clean microcentrifuge tube. Use a plastic pipette tip with the end cut off to provide a larger bore for pipetting the viscous DNA solution. Be careful not to pipette too close to the inter-phase layer. 
6. Re-extract residual DNA from the organic layer by adding $200 \mu \mathrm{L} \mathrm{1x} \mathrm{SSC} \mathrm{and} 20 \mu \mathrm{L}$ of $10 \%$ SDS to the tube. Mix well by inversion, then centrifuge. Remove the aqueous layer and pool it with the aqueous solution collected from the first phenol step (step 5). Discard organic layer.

7. Subject the pooled aqueous solution to a second round of phenol extraction (i.e. repeat steps 5-6).

8. Divide the pooled aqueous layers $(0.9 \mathrm{~mL})$ into three $0.3-\mathrm{mL}$ aliquots in microcentrifuge tubes and precipitate the DNA at room temperature by adding 2 vol $(0.6 \mathrm{~mL})$ of absolute ethanol to each tube (see Note 1). Tap and invert the tube until DNA precipitates as a single, compact, stringy, white lump. Pellet DNA by centrifugation at $13000 \mathrm{rpm}(15700$ rcf) for $10 \mathrm{sec}$. Remove supernatant and add $800 \mu \mathrm{L} 80 \%$ ethanol to wash the pellet. Centrifuge and remove supernatant.

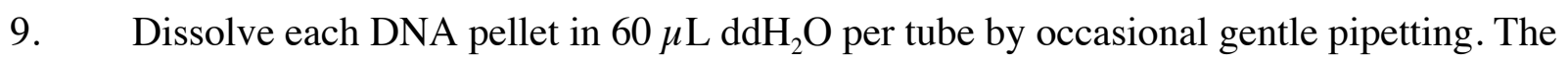
DNA should fully dissolve within $5 \mathrm{~min}$. Pool the DNA solutions from the three tubes and re-precipitate by adding $20 \mu \mathrm{L} 2 \mathrm{M}$ sodium acetate (pH 7.0) and $400 \mu \mathrm{L}$ absolute ethanol. Invert the tube until DNA precipitates, and spin in a microcentrifuge at 13000 $\operatorname{rpm}(15700 \mathrm{rcf})$ for $10 \mathrm{~s}$. Discard supernatant and wash pellet with $600 \mu \mathrm{L} 80 \%$ ethanol. Pellet DNA by spinning in a microcentrifuge at $13000 \mathrm{rpm}$ (15700 rcf) for $10 \mathrm{~s}$. Remove the supernatant. Spin again at $13000 \mathrm{rpm}(15700 \mathrm{rcf})$ in microcentrifuge for $10 \mathrm{~s}$ and discard any remaining supernatant. Vacuum-dry pellet and dissolve in $50 \mu \mathrm{L} 5 \mathrm{mM}$ Tris$\mathrm{HCl}(\mathrm{pH} 7.5)$.

\subsubsection{Extracting DNA from blood}


1. Collect venous blood into an equal volume of $1 \mathrm{x}$ SSC and store at $-80^{\circ} \mathrm{C}$. Thaw and remove $1 \mathrm{~mL}$ of blood/SSC to use for the DNA extraction. Freezing/thawing lyses almost all erythrocytes.

2. Spin the blood/SSC at $13000 \mathrm{rpm}$ (15700 rcf) in a microcentrifuge for $1 \mathrm{~min}$. This step pellets white blood cells, erythrocyte ghosts and any remaining erythrocytes. Remove supernatant and wash the pellet twice with $800 \mu \mathrm{L} 1 \mathrm{x}$ SSC, with centrifugation, to remove all hemoglobin.

3. Re-suspend the cell pellet in $450 \mu \mathrm{L} 0.2 x$ SSC by vigorously shaking by hand to produce a homogeneous cell suspension. Lyse the cells by adding $50 \mu \mathrm{L} 10 \%$ SDS (1\% final concentration), $35 \mu \mathrm{L}$ 2-mercaptoethanol (1 M final concentration) and Proteinase $\mathrm{K}$ to a final concentration of $200 \mu \mathrm{g} / \mathrm{mL}$. Mix by gently inverting the tube. Lysis will be immediately apparent.

4. $\quad$ Continue with the DNA preparation as described above (steps 4-9 in Subheading 3.1.1).

\subsubsection{Quantification of genomic DNA}

1. To quantify the DNA, add $0.6,0.9$ and $1.2 \mu \mathrm{L}$ aliquots of the DNA solution to $1 \mathrm{~mL}$ $\mathrm{ddH}_{2} \mathrm{O}$ and measure absorbances at $260 \mathrm{~nm}$ using a spectrophotometer. Add appropriate volume of $5 \mathrm{mM}$ Tris- $\mathrm{HCl}(\mathrm{pH} 7.5)$ to make a working stock DNA concentration, typically of 100 to $400 \mu \mathrm{g} / \mathrm{mL}$. Store DNA at $-80^{\circ} \mathrm{C}$.

2. Run serial dilutions of genomic DNA of a known concentration (for example, $100 \mathrm{ng}, 50$ ng, $25 \mathrm{ng}$ and $12 \mathrm{ng}$ per lane) alongside your sample on a $0.8 \%$ agarose gel in $0.5 \mathrm{x}$ TBE (with $0.2 \mu \mathrm{g} / \mathrm{ml}$ ethidium bromide in both the gel and the buffer) to verify DNA concentration and to check DNA quality. 


\subsection{Allele-specific PCR to detect crossover molecules}

To minimize contamination, keep reagents and materials used for PCR separate from general laboratory chemicals, and set up PCRs in a laminar flow hood.

\subsubsection{Designing allele-specific PCR primers}

Crossover assays use nested allele-specific PCR primers and thus require pairs of 5' and 3' selector sites (Fig. 1). These sites can be up to $13 \mathrm{~kb}$ apart, the maximum distance that can be efficiently amplified at the single DNA molecule level using our current long PCR protocol.

It is difficult to predict the behavior of an allele-specific primer. When designing them, aim for at least $50 \% \mathrm{GC}$ content, if possible. Examples of allele-specific primers that we have used successfully (23) are shown in Table 2. The most common length is 18 nucleotides, but very GC-rich allele-specific primers can be as short as 14 nucleotides. Allele-specificity is achieved by virtue of the last 3 ' base. The genomic context of the SNP for which the primer is specific mainly dictates the GC content. However, various 5' extensions can be added to boost the GC content of relatively AT-rich primers and improve primer efficiency, for example $\mathrm{C}_{4-5}$ or if necessary a synthetic 19-20 nucleotide sequence which itself can be used as a driver primer during allele-specific PCR (see primers B7RT/Ad and B7RG/Ad in Table 2 for an example).

\subsubsection{Optimizing allele-specific PCR primers}

1. To ensure efficient and specific amplification when using allele-specific primers for crossover analysis, PCR conditions must be tested empirically using long PCR (29). Set up PCRs in $0.2 \mathrm{~mL}$ tubes on a MJ Research PTC-225 Tetrad DNA Engine or other 
suitable thermal cycler, in a total volume of $10 \mu \mathrm{L}$ with $0.9 \mu \mathrm{L}$ of $11.1 \mathrm{x}$ PCR buffer supplemented with $12 \mathrm{mM}$ Tris base, $0.2 \mu \mathrm{M}$ allele-specific primer, $0.2 \mu \mathrm{M}$ universal primer (to give an amplicon 1-6 kb long), $0.03 \mathrm{U} / \mu \mathrm{L}$ Taq polymerase and $0.003 \mathrm{U} / \mu \mathrm{L} P f u$ polymerase per reaction (see Note 2).

2. To determine the optimal annealing temperature of each allele-specific primer, amplify $20 \mathrm{ng}$ of genomic DNA or equivalent whole-genome amplified DNA (30) at various annealing temperatures (typically 56,59,62 and $65^{\circ} \mathrm{C}$ ). As template, use DNA from one individual homozygous for the SNP allele at the 3' end of the allele-specific primer, and from another individual homozygous for the alternative allele in parallel reactions. If you are optimizing PCR conditions for a forward allele-specific primer, use it in combination with a universal reverse primer (22 to 24 nucleotides long) that produces a slightly shorter fragment than the amplicon you are planning to amplify in the crossover assay. If you are optimizing PCR conditions for a reverse allele-specific primer, use it in combination with a universal forward primer. As a positive control, replace the allelespecific primer with a universal primer located near the allele-specific primer site. We routinely denature the template in an initial step of $96^{\circ} \mathrm{C}$ for $1 \mathrm{~min}$, followed by 34 cycles of (denaturing at $96^{\circ} \mathrm{C}$ for $20 \mathrm{~s}, 30 \mathrm{~s}$ at annealing temperature and extension at $65^{\circ} \mathrm{C}$ for approximately $90 \mathrm{~s} / \mathrm{kb}$, see Note 3).

3. To each $10 \mu \mathrm{L}$ PCR, add $2 \mu \mathrm{L}$ all-purpose loading dye and run $6 \mu \mathrm{L}$ on a $0.8 \%$ agarose gel in $0.5 \mathrm{x}$ TBE (with both the gel and the buffer containing $0.5 \mu \mathrm{g} / \mathrm{mL}$ ethidium bromide), with $200 \mathrm{ng}$ of size standard alongside your samples. Photograph the gel, including very long exposures to visualize any very faint PCR products (see Note 4). 


\subsubsection{Determining linkage phase of donors to be used in crossover assays}

1. From your collection of semen donors, identify individuals who are heterozygous for selector SNP sites (F1, F2, R1, R2 in Fig. 2) and who also carry internal heterozygosities suitable for mapping crossover breakpoints in recombinant molecules.

2. If selector $\mathrm{SNP}$ sites $\mathrm{F} 1 / \mathrm{F} 2$ and $\mathrm{R} 1 / \mathrm{R} 2$ are separated by a putative recombination hotspot, then they will most likely be in free association and their linkage phases will therefore be unknown. Determine linkage phase, i.e. haplotypes, for these SNP sites by allele-specific PCR using allele-specific primer pairs F1-R2, F2-R1 and F2-R2 in all four possible combinations of each allelic primer (see Fig. 2). If, as is likely, F1 and F2 lie outside a hotspot and are in strong association, then their linkage phase can be inferred from genotype data; the same will probably be true for R1 and R2. Under these circumstances, only one phasing assay needs be done, e.g. F2-R2, to determine complete 4-marker haplotypes. Under no circumstances should phasing be done using the outside primers

F1-R1, as this will generate PCR products that could easily contaminate primary PCRs in subsequent crossover analyses.

3. Retain the positive PCR products from the phasing assay and store at $-20^{\circ} \mathrm{C}$. These separated haplotypes will be needed later for haplotyping internal SNPs during crossover breakpoint mapping (see Section 3.3.1).

\subsubsection{Amplification of crossover molecules from sperm DNA}

Sperm crossover analysis is feasible once suitable pairs of allele-specific primers for primary PCR and for nested secondary PCR have been developed. Modification of primers (see 
Section 3.2.1) may prove necessary to develop primer pairs that operate with good efficiency and specificity at the same annealing temperature.

One further problem is recombination frequency. Human crossover hotspots vary widely in sperm crossover frequency, from $0.0004 \%$ to $1 \%$ at currently characterized hotspots, and the crossover frequency over the test interval will not be known a priori. An initial pilot crossover assay over widely varying inputs of sperm DNA is therefore necessary. Given that a haploid human genome contains 3 pg DNA, then 6 pg sperm DNA will contain on average one molecule of each haplotype. Not all DNA molecules will amplify during PCR due to primer inefficiency and DNA damage; our experience indicates that typically $50 \%$ of molecules will generate PCR products. Thus 12 pg genomic DNA will contain one amplifiable molecule of each haplotype, and a PCR seeded with 1000 molecules should contain an input of $12 \mathrm{ng}$ DNA.

Crossover assays can also generate spurious positive PCRs, usually because of incomplete specificity of an allele-specific primer leading to bleed-through of one or other progenitor haplotype in the assay. Jumping PCR artifacts arising from annealing between progenitor haplotypes can also occur, though these are generally rare (see also Section 3.2.4.2). Both can be controlled in the pilot assay by including blood DNA from the semen donor. We have never seen an authentic crossover in blood DNA, which therefore provides an ideal negative control.

It is also advisable to include positive controls in the pilot assay by spiking some PCRs with genomic DNA from an individual carrying haplotypes showing the opposite linkage phase between 5 ' and 3 ' selector sites; such individuals should have been identified in the linkage phasing assay (see Section 3.2.3). Obviously, such genomic DNA should be handled with 
extreme caution during PCR setup, given its ability to cause major contamination of the assay with "crossover" molecules.

\subsubsection{First round of PCR}

To detect crossover molecules, amplify multiple aliquots of sperm DNA using the outside primer pair F1-R1 in recombinant phase (Fig. 2). A typical 96-well plate setup would contain six rows of sperm DNA with 100, 200, 400, 800, 1600 and 3200 molecules per well (1.2-38.4 ng DNA per PCR), plus two rows of blood DNA (one row at 800 and one at 3200 molecules per well). Positive controls are obtained by spiking a few wells with $0.5 \mu \mathrm{L} 200 \mathrm{ng} / \mathrm{mL}$ genomic DNA (8 amplifiable molecules) from a control individual (see Section 3.2.4). This setup will screen 76,000 molecules for crossovers and will detect crossover molecules even at recombination frequencies as low as $0.0013 \%$.

1. Set up PCRs as in Subheading 3.2.2, step 1, but in total volumes of $8 \mu \mathrm{L}$. Start PCRs with an initial denaturation step at $96^{\circ} \mathrm{C}$ for $1 \mathrm{~min}$, followed by cycling conditions determined in the optimization experiments. Generally, 26 cycles of amplification should be used in the primary PCR.

2. Immediately dilute PCR products with $35 \mu \mathrm{L} 5 \mathrm{mM}$ Tris- $\mathrm{HCl} \mathrm{pH} 7.5$ plus $2 \mu \mathrm{g} / \mathrm{mL}$ high molecular weight herring or salmon DNA carrier, or if necessary proceed to S1 nuclease digestion (see Section 3.2.4.2 and Note 5).

\subsubsection{S1 nuclease digestion (optional, see Note 5)}


1. Set up the same number of fresh $0.2 \mathrm{~mL}$ PCR tubes as you have in the first round of PCR, or a fresh plate. To each fresh tube, or each well in the fresh plate, add $5 \mu \mathrm{L} \mathrm{S} 1$ digestion mix containing $0.7 \mathrm{U} / \mu \mathrm{L} \mathrm{S} 1$ nuclease.

2. Take $0.5 \mu \mathrm{L}$ of each primary PCR product and add to S1 digestion mix. Mix by pipetting up and down three times.

3. Leave samples to digest at room temperature for $20 \mathrm{~min}$.

4. Add $45 \mu \mathrm{L}$ of $\mathrm{S} 1$ dilution buffer to each digest to bring the $\mathrm{pH}$ above 7 . Keep on ice. Store $\mathrm{S} 1$ digests at $-20^{\circ} \mathrm{C}$. They are stable for at least 6 months.

\subsubsection{Second round of PCR}

1. Set up each of the secondary (nested) PCRs in a $10 \mu \mathrm{L}$ total volume. Seed each PCR with $0.5 \mu \mathrm{L}$ of diluted primary PCR product or $1.6 \mu \mathrm{L}$ of S1-digested primary PCR product. Use allele-specific primers targeted towards inner SNP selector sites in recombinant phase. As in section 3.2.4.1., start all PCRs with an initial denaturation step at $96^{\circ} \mathrm{C}$ for 1 minute, followed by optimized cycling conditions. Amplify the secondary PCRs for 3035 cycles.

2. Add $2 \mu \mathrm{L}$ all-purpose loading dye to each tube, and run out $5 \mu \mathrm{L}$ aliquots on an agarose gel in the presence of $0.5 \mu \mathrm{g} / \mathrm{mL}$ ethidium bromide in both the gel and the buffer. A successful assay will show as positive secondary PCRs increasing in frequency with increasing sperm DNA input, a lack of PCR products in blood DNA reactions, and strongly positive signals in the positive control PCRs.

\subsubsection{Calculating crossover frequencies}

20. Kauppi et al. 
Estimate the crossover frequency from the numbers of positive and negative PCR reactions at each input of sperm DNA. To illustrate the different steps of crossover scoring, the hypothetical crossover assay shown in Fig. 3 (8 input pools of 2000, 600 and 200 molecules each, with 7, 3 and 1 crossover positive reactions recovered, respectively) is used as an example throughout sections below.

1. Estimate the frequency of crossovers (m) in input DNA for each input pool by Poisson approximation:

$\mathrm{m}=-\ln$ (number of negative reactions/total number of reactions).

2. Maximum-likelihood methods (software written by A.J.J., available upon request) can be used to estimate crossover frequency more accurately by combining data from all input pool sizes. The mean crossover frequency calculated for the example data set in Fig. $\mathbf{3}$ is $0.89 \times 10^{-3}$, with lower and upper $95 \%$ confidence intervals of $0.41 \times 10^{-3}$ and $1.72 \times 10^{-3}$.

\subsubsection{Bulk recovery of crossover molecules}

1. Use the crossover frequency estimates from Subheading 3.2.4.4 to estimate optimal DNA pool sizes for efficient recovery of crossover molecules. Accurate definition of crossover profiles in the test interval requires the recovery and mapping of about 100 crossovers.

2. Recover crossovers from a single 96-well plate by using varying inputs of sperm DNA containing from 0.6 to 1.5 crossover molecules per well. Set up PCRs such that at the lowest inputs $45 \%$ of PCR reactions will be positive (and consequently $74 \%$ of positive reactions will be derived from a single input crossover molecule). The corresponding figures at the highest inputs are $88 \%$ and $43 \%$, indicating that the majority of positive 
PCRs will contain DNA from more than one crossover, though not all molecules will necessarily show different exchange points. Mixed products derived from two or more crossovers with different exchange points can be readily identified during crossover breakpoint mapping (see Section 3.3.4).

\subsubsection{Reciprocal crossover assays}

The crossover assay shown in Fig. 1 recovers black-to-white crossover molecules. Reciprocal crossover products can be recovered by changing all allele-specific primers to their alternative allele, to recover white-to-black crossovers. The assay must take into account the different annealing specificities of the alternative primers. Assays performed in each orientation are independent of each other and provide a useful test of reciprocity; equal crossover frequencies should be seen in both assay orientations. Also, reciprocal crossover data provide a powerful probe for detecting differences in recombination initiation frequencies on the two haplotypes in an individual (31).

\subsection{Mapping locations of crossovers}

\subsubsection{Third round of PCR}

1. Re-amplify secondary PCRs using universal PCR primers located just internal to the secondary PCR primer SNP sites. Set up PCRs in total volumes of 10-20 $\mu \mathrm{L}$, seeded with $0.5 \mu \mathrm{L}$ of secondary PCR product. Reserve two wells on the PCR plate and seed with one or other separated progenitor haplotype prepared in Subheading 3.2.3, step 3. Amplify for 35 cycles to ensure that all reactions now amplify, even those seeded with blood DNA and crossover negative sperm reactions. 
2. Add $2.5-5 \mu \mathrm{L}$ all-purpose loading dye, and check that PCR amplification has occurred to a uniform high level by electrophoresis of $0.6 \mu \mathrm{L}$ of PCR product/loading dye mix on an agarose gel. Only a few reactions need be tested.

\subsubsection{Transferring reactions onto dotblots (see Note 6)}

1. Cut two pieces of 3MM paper, plus as many pieces of nylon membrane as you need replica filters, to the size of your 96-well dotblot manifold (we use model DHM-96, SciePLAS, Southam, UK). Soak paper and membranes in $\mathrm{ddH}_{2} \mathrm{O}$ for a few minutes.

2. Place the two pieces of $3 \mathrm{MM}$ paper on the dotblot manifold. Overlay with one piece of nylon membrane. Assemble the dotblot manifold, making sure that the securing nuts are uniformly fastened but not over-tightened. Apply a vacuum to the assembled manifold.

3. Add $30 \mu \mathrm{L}$ of denaturing solution ( $0.5 \mathrm{M} \mathrm{NaOH}, 2 \mathrm{M} \mathrm{NaCl}, 25 \mathrm{mM}$ EDTA) per replica filter (e.g. $180 \mu \mathrm{L}$ denaturing mix if you wish to make 6 replica filters) directly to PCRs from Subheading 3.3.1 and mix well by pipetting up and down, or by sealing the plate, mixing and centrifuging.

4. Using a multichannel pipette, load $35 \mu \mathrm{L}$ denatured DNA into each well of the manifold. Once all samples are loaded and the liquid has been pulled through the membrane, add $150 \mu \mathrm{L} 2 \mathrm{x}$ SSC to each well to neutralize DNA. Bake dotblots for $10 \mathrm{~min}$ at $+80^{\circ} \mathrm{C}$ and covalently link the DNA to the membrane by UV exposure in a UV crosslinker.

\subsubsection{ASO hybridization}

1. Label each ASO by mixing $1 \mu \mathrm{L} 10 \mathrm{x}$ kinase mix, $0.2 \mu \mathrm{L}\left[\gamma^{32} \mathrm{P}\right]-\mathrm{ATP}, 7.8 \mu \mathrm{L} \mathrm{ddH}_{2} \mathrm{O}$, and $0.35 \mu \mathrm{L} \mathrm{T} 4$ polynucleotide kinase $(10 \mathrm{U} / \mu \mathrm{L})$ in a screw-top microcentrifuge tube at room 
temperature (see Note 7). Add $1 \mu \mathrm{L}$ of $8 \mu \mathrm{g} / \mathrm{mL}$ ASO. Incubate at $37^{\circ} \mathrm{C}$ in a heat block for 1-3 h. Add $20 \mu \mathrm{L}$ kinase stop solution. The probe can be used immediately for hybridization, or stored at $+4^{\circ} \mathrm{C}$ or $-20^{\circ} \mathrm{C}$ for a few days.

2. Soak dotblots in 3x SSC. Transfer each to a small hybridization bottle with the DNA side facing inwards.

3. Pre-hybridize dotblots at $49^{\circ} \mathrm{C}$ for 5 minutes in $2 \mathrm{~mL}$ TMAC hybridization solution. Discard solution. Add $2.5 \mathrm{~mL}$ fresh hybridization solution. Incubate in rotator oven at $49^{\circ} \mathrm{C}$ for $5 \mathrm{~min}$.

4. Add ${ }^{32} \mathrm{P}$-labelled ASO and $40 \mu \mathrm{L}$ unlabelled $8 \mu \mathrm{g} / \mathrm{mL}$ ASO of the opposite allele as competitor. Hybridize in rotator oven at $49^{\circ} \mathrm{C}$ for $1-2 \mathrm{~h}$.

5. Wash membranes inside bottles in two changes of $2-3 \mathrm{~mL}$ TMAC wash solution at $53^{\circ} \mathrm{C}$ in rotator oven for approximately $5 \mathrm{~min}$ per wash, followed by one $15 \mathrm{~min}$ wash with 4 mL TMAC wash solution.

6. Rinse membranes twice in $\sim 5-10 \mathrm{~mL}$ of $3 \mathrm{x}$ SSC in the bottles at room temperature, then transfer the membranes to a Pyrex tray with 3x SSC and wash at room temperature a few times.

7. Blot excess liquid off membranes with $3 \mathrm{MM}$ paper, seal them in Saran wrap and autoradiograph at room temperature or at $-80^{\circ} \mathrm{C}$ with an intensifier screen. Do not allow the blot to dry out (see Note 8).

8. Combine all membranes in a Pyrex dish and remove the probe with at least 10 changes of $100 \mathrm{~mL}$ boiling $0.1 \%$ SDS. Monitor probe removal using a Geiger-Muller meter; $>99 \%$ of label should be removed. Re-probe the same membrane with the ASO corresponding 
to the alternative allele of same SNP site. Dotblots can be re-probed at least 10 times without loss of signal.

\subsubsection{Mapping crossover breakpoints}

ASO typing reveals the status of each internal SNP site in each crossover-positive PCR. The presence of progenitor haplotypes on the same dotblot allows internal alleles to be assigned to one or other progenitor haplotype, essential for the determination of crossover breakpoints. Including crossover negative and blood PCRs can provide useful information on bleed-through PCR amplification of progenitor haplotypes and help identify potentially problematic allelespecific primers used in crossover recovery. Hypothetical examples of dotblot data are shown in Fig. 4.

Crossover-positive reactions can either be "simple" (see e.g. dot number 11 in Fig. 4BC), or "mixed", i.e. giving a positive signal upon hybridization with both alleles of some SNP sites (see e.g. dot number 1 in Fig. 4B-C). "Simple" ones contain only one class of crossover; they might contain more than one crossover molecule, but all crossovers have their breakpoint in the same inter-SNP interval. "Mixed" reactions contain two or more different crossovers. We score them as two crossovers, one with a breakpoint 5 ' to where a succession of one or more mixed SNP sites starts, and the other 3' to where the mixture finishes (Table 3B). The estimate of the number of crossovers will always be conservative - simple reactions may contain more than one crossover, but only one will be scored; mixed reactions may contain more than two crossovers, but only two will be scored. The true number of crossovers will therefore be higher, and can be estimated for each inter-marker interval by Poisson correction. This involves combining data (number of PCRs positive and negative for a given type of crossover) over all 
input pool sizes. Note that some PCRs will not be scorable for certain types of crossover; specifically, if a PCR contains a succession of two or more mixed sites, then each interval between mixed sites will not be scorable for a crossover in that interval, since such crossovers will be masked by the two definite exchanges that create the succession of mixed sites. Such PCRs should be ignored in the Poisson correction.

Crossovers may occasionally be observed in the end intervals (furthest $5^{\prime}$ or $3^{\prime} \mathrm{SNP}$ interval assayed by ASO hybridization, see dot 7 in Fig. 4C). Crossovers of this type could either have their breakpoint in the interval between the inner selector site and the nearest internal heterozygous SNP site, or they could be PCR artifacts arising from bleed-through amplification of one or other haplotype. Analysis of crossover-negative PCRs and of blood DNA can show whether such bleed-through amplification is a reasonable explanation. If not, then score these end-interval crossovers but interpret with caution. If bleed-through is a significant problem, then ignore the end interval when determining the crossover profile over the test interval.

1. Score ASO signals on dotblots. Order crossovers in a table according to the location of their breakpoints, $5^{\prime}$ to $3^{\prime}$. Count the number of crossovers for each SNP interval (Table 3C). Maximum-likelihood methods (software written by A.J. Jeffreys, available upon request) can then be used to estimate the mean frequency of crossovers in each interval, taking into account in which input pools the crossovers were observed (Table 4A).

2. Adjust the number of molecules screened for each SNP interval where mixtures are observed by excluding pools that contain sequential mixed sites spanning the SNP interval (see intervals SNP4-SNP5 and SNP5-SNP6 in Table 4A). For each SNP interval, multiply the maximum-likelihood Poisson estimate of recombination frequency by the 
total number of molecules screened, to yield the Poisson-corrected number of crossovers adjusted for any missing data from PCRs showing sequential mixed sites (Table 4B). Calculate the recombination activity in $\mathrm{cM} / \mathrm{Mb}$ for each SNP interval as follows:

(Poisson-corrected number of crossovers/total number of molecules screened) $\mathrm{x} 100=$ recombination fraction in $\mathrm{cM}$,

then:

(recombination fraction in $\mathrm{cM} /$ length of interval in $\mathrm{bp}$ ) $\mathrm{x} 10^{6}=$ recombination activity per unit physical length in $\mathrm{cM} / \mathrm{Mb}$.

Recombination activity across the example interval in Fig. 4A is shown in Fig. 4D and

Table 4B.

\subsection{Detecting gene conversions and crossovers using the half-crossover assay}

Recombination can generate both crossovers and non-exchange gene conversions. The latter often involves the transfer of just a single SNP marker between haplotypes and cannot be detected in crossover assays. An alternative approach that is capable of detecting such events is the halfcrossover assay (Fig. 5) in which nested allele-specific PCR on sperm DNA is directed to markers only at one end of the test interval, with universal primers being used at the other end. In the absence of recombination, PCR products will only be generated from the selected haplotype. Recombinants can be detected by the presence of markers from the unselected haplotype, with crossovers and conversions each giving distinct patterns of positive markers. PCR amplifications are essentially as described in Sections 3.2.4.1 and 3.2.4.3, with recombinant detection as described in Sections 3.3.2 and 3.3.3 (see Note 9). 
1. For primary PCR, set up a long PCR master mix $(800 \mu \mathrm{L})$ containing the outermost allelespecific primer, the distal universal primer plus typically $48 \mathrm{ng}$ sperm DNA. Array $8 \mu \mathrm{L}$ aliquots into a 96-well plate to give $0.48 \mathrm{ng}$ sperm DNA per PCR (40 amplifiable molecules of each haplotype for this input). Amplify for 26 cycles using annealing temperature conditions optimal for the allele-specific primer. Note that optimization is simpler than for the full crossover assay since only one allele-specific primer is being used.

2. Dilute the primary PCR products with $35 \mu \mathrm{L} 5 \mathrm{mM}$ Tris- $\mathrm{HCl} \mathrm{pH} 7.5$ plus $2 \mu \mathrm{g} / \mathrm{mL}$ high molecular weight herring or salmon DNA as carrier. Seed $15 \mu \mathrm{L}$ secondary PCRs containing the nested allele-specific primer and nested universal primer with $0.6 \mu \mathrm{L}$ diluted primary PCR product and amplify under optimized conditions for 36 cycles.

3. Test $0.6 \mu \mathrm{L}$ of a selection of secondary PCRs by agarose gel electrophoresis and staining with ethidium bromide. Check that the correct-sized PCR product (typically 5-10 kb in these assays) has been generated and that PCR product yields are high and uniform over the reactions.

4. Before dotblotting, add the non-selected haplotype, amplified separately, to five wells on the secondary PCR plate such that the ratio of non-selected to selected haplotype PCR products is $1: 10,1: 30,1: 100,1: 300$ and 1:1000. These wells will serve as positive controls to determine the level of allele-specificity of hybridization for each ASO, as well as estimating the proportion of recombinant DNA in pools showing a putative crossover or conversion.

5. Denature the secondary PCRs and prepare as many replica dotblots as required (see Section 3.3.2). 
6. Hybridize dotblots with each ASO to detect alleles from the non-selected haplotype (see Section 3.3.3).

7. Score autoradiographs for the presence of a crossover or non-exchange conversion in each secondary PCR. Crossovers will be clearly evident from the presence of a succession of positive markers extending continuously towards the distal end of the test interval (Fig. 5). Conversions involving more than one SNP site will also be clear from adjacent markers being positive. Single-site conversions will show as single markers with a positive signal, and with a signal level corresponding to at least $1 \%$ of PCR product being derived from the recombinant. Crossovers (which are always genuine recombinant molecules) provide a useful internal control to demonstrate proper signal intensities. Very faint $(<<1 \%)$ singlesite signals should be rejected as PCR mis-incorporations. Blood DNA, which is free from recombinants, can be processed in parallel to give more information on the likely incidence and signal intensities of mis-incorporation artifacts.

8. The gene conversion frequency for each SNP site can be calculated by excluding all crossover-positive PCRs in which conversions might be masked (Fig. 5), and counting the number of conversion-positive $(p)$ and conversion-negative $(n)$ PCRs for the remaining $p+n$ reactions. The Poisson-corrected total number of conversions $(c)$ per PCR is estimated by $-\ln [n /(p+n)]$, and the conversion frequency is thus given by $c / t$, where $t$ is the mean number of amplifiable molecules of each haplotype present per PCR (in this example, 40).

9. If desired, crossover-positive PCRs can be further analyzed by allele-specific PCR directed to a distal SNP site (Fig. 5). This allows crossover molecules and non-crossovers (including progenitors) to be amplified separately prior to mapping. 


\subsection{DNA enrichment by allele-specific hybridization (DEASH)}

DEASH is a pre-PCR DNA enrichment strategy that both facilitates the detection of de novo non-crossover gene conversion events and serves to verify their authenticity (24). By hybridizing a biotinylated ASO to denatured sperm DNA, molecules containing a known singlenucleotide variant can be captured on streptavidin-coated paramagnetic beads whilst those bearing the alternative variant can be removed by washing. On subsequent release from the beads, this specifically enriched single-stranded DNA can be analyzed by allele-specific PCR (see Section 3.2). Gene conversion and crossover events are thus detected by enriching for a variant specific to one haplotype then amplifying pools of this enriched DNA using primers specific to the opposite haplotype (see Fig. 6).

The enrichment procedure reduces the complexity of the DNA and therefore improves the signal-to-noise ratio in the PCR such that pools of enriched DNA derived from large amounts of genomic DNA can be screened for recombinants. Since gene conversion tracts are very short (25), the ability to detect such events depends on having SNP markers very close to the center of the hotspot. If there is more than one SNP requiring analysis, then separate enrichment of each SNP will need to be carried out. The level of enrichment achievable can be 300 -fold or higher. Unlike the half crossover assay alone (Section 3.4), pre-processing DNA with DEASH allows the detection of very rare events, with a frequency of $10^{-6}$ or lower, even if they only affect a single SNP site. These single-site conversions should only affect the selected SNP and not a nonselected SNP. This provides validation for such events and helps establish that they are not PCR mis-incorporations (see also Section 3.4.7).

\subsubsection{The DEASH Procedure}

20. Kauppi et al. 
To maximize the yield of recovered DNA, cleave sperm genomic DNA with a restriction enzyme that cuts just outside the region of interest; undigested DNA gives very poor yields. We have successfully used the DEASH protocol to enrich for genomic restriction fragments up to $12.5 \mathrm{~kb}$ in size. Digest according to the manufacturer's instructions, supplemented if necessary with spermidine trichloride to a final concentration of $4 \mathrm{mM}$ to improve digestion. After digestion, ethanol precipitate the genomic DNA, wash with $80 \%$ ethanol, dry and dissolve in 5 $\mathrm{mM}$ Tris- $\mathrm{HCl}(\mathrm{pH} 7.5)$ to a final concentration of $0.2-1 \mathrm{mg} / \mathrm{mL}$ (see also Section 3.1.1, steps 89).

It is necessary to determine empirically the annealing temperature $\left(\mathrm{A}^{\circ}\right)$ of each biotinylated ASO before bulk genomic DNA is processed in order to maximize both yield and the degree of allele separation. As a guide, the relationship between optimal annealing temperature and $\mathrm{GC}$ content of a bio-ASO approximates to $29.6^{\circ} \mathrm{C}+0.318(\% \mathrm{GC})^{\circ} \mathrm{C}$ in the buffer used for hybridization (24). However, the efficiency of allele separation is very much ASO-dependent (see Table 5).

\subsubsection{Annealing temperature titration}

Throughout the procedure use dedicated "pre-PCR" pipettes for manipulations. Typically, we test annealing temperatures over the range of $30-60^{\circ} \mathrm{C}$ in $5^{\circ} \mathrm{C}$ increments using 0.1 $\mu \mathrm{g}$ of digested genomic DNA in a $20 \mu \mathrm{L}$ volume. The following should be scaled according to the number of annealing temperatures to be tested.

1. Set "annealing" waterbath to $\mathrm{A}^{\circ} \mathrm{C}$ and "elution" waterbath to $60^{\circ} \mathrm{C}$.

2. Prepare $210 \mu \mathrm{L}$ of $1 \mathrm{x}$ DHB for bead preparation, keep at room temperature; $21 \mu \mathrm{L} 10 \mathrm{x}$

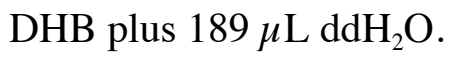


3. Prepare $100 \mu \mathrm{L}$ of DHB/BSA wash solution and place in "annealing" waterbath; $10 \mu \mathrm{L}$ 10x DHB, $88 \mu \mathrm{L} \mathrm{ddH}{ }_{2} \mathrm{O}$ plus $2 \mu \mathrm{L} 500 \mu \mathrm{g} / \mathrm{mL}$ BSA.

4. Aliquot $50 \mu \mathrm{L}$ of ED solution, keep at room temperature.

5. Aliquot a further $100 \mu \mathrm{L}$ of ED solution and place in "elution" waterbath.

6. Gently agitate to re-suspend the M-280 Streptavidin Dynabeads, then aliquot $21 \mu \mathrm{L}$ into a siliconized $1.5 \mathrm{~mL}$ Eppendorf tube. Pre-wash the beads twice in 1x DHB buffer: place the tube in the Dynal magnetic particle concentrator, leave for $10 \mathrm{~s}$, then twist each way until the beads have formed a small mass, aspirate off liquid, then remove tube from concentrator and re-suspend bead mass in $100 \mu \mathrm{L} 1 \mathrm{x}$ DHB by gentle pipetting, repeat procedure. Finally, re-pellet beads and re-suspend in $1.5 \mu \mathrm{L}$ of $1 \mathrm{x}$ DHB (i.e. $1 / 14^{\text {th }}$ the original volume of the beads). Keep on ice until needed.

7. In a $0.2 \mathrm{~mL}$ PCR tube add $2 \mu \mathrm{L} 10 \mathrm{x}$ DHB, $1.5 \mu \mathrm{L} 5 \mu \mathrm{M}$ biotinylated ASO, $1 \mu \mathrm{L} 30 \mu \mathrm{M}$ non-biotinylated competitor ASO, $0.1 \mu \mathrm{g}$ digested genomic DNA and make up to $20 \mu \mathrm{L}$ with $\mathrm{ddH}_{2} \mathrm{O}$.

8. Place tube in a PCR machine and denature the DNA at $96^{\circ} \mathrm{C}$ for $75 \mathrm{~s}$, then step down the temperature to allow the bio-ASO to anneal to the target DNA starting at $\mathrm{A}+9^{\circ} \mathrm{C}$ and going down to $\mathrm{A}+1^{\circ} \mathrm{C}$ in $1{ }^{\circ} \mathrm{C}$ steps for $20 \mathrm{~s}$ per step. Anneal at $\mathrm{A}^{\circ} \mathrm{C}$ for $2 \mathrm{~min}$.

9. During the annealing step, pre-warm a siliconized $1.5 \mathrm{~mL}$ Eppendorf tube containing 1.3 $\mu \mathrm{L}$ of washed beads in a waterbath set at $\mathrm{A}^{\circ} \mathrm{C}$.

10. Transfer the contents of the PCR tube to the pre-warmed tube containing the beads, mix extremely gently and incubate for 10 min at $\mathrm{A}^{\circ} \mathrm{C}$. Ensure the beads remain suspended during this time by very carefully flicking the contents of the tube every couple of 
minutes. Binding of the bio-ASO to the streptavidin-coated beads appears to be complete within about 5 minutes, even for large DNA targets.

11. Use the magnetic concentrator to pellet the beads. Remove the supernatant containing the unbound DNA, but keep this fraction if you wish to re-extract DNA from it (see Section

\subsection{4, step 2)}

12. Re-suspend the beads and captured DNA hybrids in $50 \mu \mathrm{L}$ of the DHB/BSA wash solution. Pipette very gently and transfer to a fresh siliconized $1.5 \mathrm{~mL}$ tube and incubate at $\mathrm{A}^{\circ} \mathrm{C}$ for $1 \mathrm{~min}$.

13. Repeat steps 11-12, to remove the last traces of unbound DNA.

14. Repeat steps $11-12$, this time re-suspending the beads in the $50 \mu \mathrm{L}$ of room temperature elution buffer ED and transferring to a fresh siliconized tube at the same temperature.

15. Repeat step 14 , using the $60^{\circ} \mathrm{C}$ elution buffer.

16. Incubate for $2 \mathrm{~min}$ at $60^{\circ} \mathrm{C}$ to release the target DNA from the biotinylated ASO/bead complex. Use the magnetic concentrator to remove the beads and recover the eluted DNA (supernantant) into a siliconized $1.5 \mathrm{~mL}$ tube.

17. Turn up "elution" waterbath containing the remaining elution buffer to $70^{\circ} \mathrm{C}$.

18. Repeat steps $15-16$ to release any remaining DNA.

\subsubsection{Determining yield and allele separation}

Yields of each haplotype are estimated by comparing allele-specific PCR amplification (see Section 3.2) of a range of concentrations of input DNA with recovered DNA on ethidium bromide-stained gels. This also allows assessment of the degree of allele separation (Fig. 7). The PCR is limited to the exponential phase of amplification and yield estimation must take into 
account the fact that unfractionated double-stranded DNA results in twice as much PCR product as an equal number of recovered single-stranded molecules. Typically, $10 \mu \mathrm{L}$ PCRs are seeded with $4 \%$ of each eluate $(2 \mu \mathrm{L})$ and the control input series corresponds to that expected for $100 \%$ down to $0.5 \%$ yields. In addition to evaluating the optimal annealing temperature, the best elution temperature can also be determined. Note that the elution buffer ED is $0.14 \mathrm{x}$ PCR buffer less dNTPs and BSA; PCR setup should take this buffer into account.

\subsubsection{Processing bulk genomic DNA by DEASH}

1. Up to $2 \mu \mathrm{g}$ of digested genomic DNA can be processed per $20-\mu \mathrm{L}$ volume as described in Section 3.5.1. If larger quantities are required then set up multiple $40 \mu \mathrm{L}$ volumes with 4 $\mu \mathrm{g}$ of DNA each and double the volumes described in the protocol. In our experience, it is difficult to keep the beads suspended in larger volumes than this.

2. Yields can be increased by re-extracting the remaining target from the unbound fraction obtained in step 11 of Section 3.5.1. Place the unbound fraction in a $0.2 \mathrm{~mL}$ PCR tube and add $5 \mu \mathrm{M}$ biotinylated ASO to a final concentration of $0.375 \mu \mathrm{M}$. Proceed from step 8 of Section 3.5.1 using the optimal annealing and elution temperatures. This reextraction can be set up immediately on separating the first unbound DNA; re-extraction thus proceeds through the denaturation, annealing and binding steps whilst washing and elution is carried out on the initially-bound DNA. More than $95 \%$ of the recoverable DNA will be obtained from three rounds of re-extraction. However, the degree of purification can decrease several fold with each re-extraction.

3. Recovered DNA can also be subjected to a second round of purification using the same biotinylated ASO. The same degree of purification is achieved at each cycle such that a 
20-fold purification obtained with one round equates to a 400 -fold purification after the second. However, the percentage recovery per round remains roughly constant such that the yield declines proportionally. To re-purify the eluted DNA in ED buffer, add DHB to $1 \mathrm{x}$ (note that ED is already $0.14 \mathrm{x}$ DHB), biotinylated ASO to $0.375 \mu \mathrm{M}$ and nonbiotinylated competitor ASO to $1.5 \mu \mathrm{M}$. Proceed as for the first purification, starting at

\section{step 8 of Section 3.5.1.}

4. When target fragments contain Alu elements, yields can sometimes be improved by adding Alu competitor DNA to suppress networking of the genomic DNA via Alu-Alu hybridization during the annealing step of the DEASH procedure. The competitor can be made by PCR using consensus sequence-derived primers Alu-F and Alu-R. Initially seed a $10 \mu \mathrm{L}$ PCR containing $0.9 \mu \mathrm{L}$ of $11.1 \mathrm{x}$ PCR buffer (see Section 2.2.1) along with 0.5 $\mu \mathrm{M}$ of each primer and $50 \mathrm{ng}$ of human genomic DNA. Cycle for $\left[96^{\circ} \mathrm{C} 20 \mathrm{~s}, 52^{\circ} \mathrm{C} 30 \mathrm{~s}\right.$, $70^{\circ} \mathrm{C}$ for $1 \mathrm{~min}$ ] for 2 cycles, followed by a further 2 cycles annealing at $55^{\circ} \mathrm{C}$ and then finally 12 cycles annealing at $58^{\circ} \mathrm{C}$. The initial low annealing temperature should allow amplification of diverged Alu elements whilst the later higher annealing temperature is optimal for this primer pair. Re-amplify by seeding $400 \mu \mathrm{L}$ of PCR mix with $4 \mu \mathrm{L}$ of the PCR product and splitting mix into eight $50-\mu \mathrm{L}$ reactions. Use 17 cycles at the higher annealing temperature, gel-purify the 270 bp product, ethanol precipitate and dissolve in $100 \mu \mathrm{L} 5 \mathrm{mM}$ Tris-HCl pH 7.5. Estimate yield by gel electrophoresis. Irradiate on a UV transilluminator for $5 \mathrm{~min}$ to render the DNA recalcitrant to further PCR amplification. Add the Alu competitor to a final concentration of $2.5 \mu \mathrm{g} / \mathrm{mL}$ at step 7 of Section 3.5.2.

5. $\quad$ Screen enriched DNA for recombinants as described in Section 3.5.5. 


\subsubsection{Detecting gene conversions and crossovers in DNA enriched by DEASH}

Recombinant detection in the half-crossover assay is limited by the progenitor haplotype molecules present in each pool. As described in Section 3.5, DEASH allows genomic DNA to be fractionated to enrich for molecules containing a specific allele at a given SNP, thus depleting fractionated DNA in one of the two progenitor haplotypes. As shown in Fig. 6B, a half-crossover assay directed to the depleted haplotype will remove the selected progenitor haplotype, greatly facilitating the detection of crossover and conversion events. By way of example, suppose that

DEASH has been performed on $12 \mu \mathrm{g}$ sperm DNA $\left(10^{6}\right.$ amplifiable molecules of each haplotype) to give a 200 -fold enrichment of the selected haplotype and a $50 \%$ yield. The enriched single-stranded DNA will therefore contain 500,000 molecules of the selected haplotype and 2,500 remaining molecules of the unselected haplotype. The DNA can thus be analyzed by the half crossover method, amplifying the unselected haplotype exactly as in Section 3.4, in a single plate with just 26 (2,500/96) progenitor molecules per PCR, allowing the detection of recombinants (both crossovers and conversions) as rare as $0.0002 \%(1 / 500,000)$. Recombinant detection and interpretation, and the Poisson correction of data, are performed exactly as in the half crossover assay (see Section 3.4).

\section{Notes}

1. At this step, it is not necessary to add salt, as there is enough SSC and SDS in the sample to allow the DNA to precipitate.

2. Allele-specific primers can sometimes behave slightly differently in each batch of $11.1 \mathrm{x}$ PCR buffer. It is best to make a large enough batch of $11.1 \mathrm{x}$ buffer to last through optimizations and the desired crossover assays. If you run out of $11.1 \mathrm{x}$ buffer in the 
middle of a crossover assay, you may need to re-optimize the allele-specific primers in the new batch of buffer.

3. We find that using this relatively low extension temperature of $65^{\circ} \mathrm{C}$ increases the efficiency of amplification, especially for AT-rich amplicons, and reduces the incidence of jumping-PCR artifacts arising by annealing of incompletely extended PCR products. This reduction is especially important in the final crossover assay in which jumping PCR could generate false recombinants.

4. An ideal allele-specific primer will show, at one or more annealing temperatures, both good efficiency with PCR product yields from the correct homozygote comparable to those obtained with a universal primer, and good specificity with little if any detectable PCR product being generated from DNA from someone homozygous for the alternative allele. Low-efficiency primers can be modified by adding synthetic 5' extensions (see Section 3.2.1) and low-specificity primers can be shortened by one or more bases; these modifications can sometimes, but not always, substantially improve primer performance.

5. This step removes single-stranded DNA from PCR products prior to re-amplification with nested primers. S1 digestion improves the specificity of nested allele-specific primers and removes PCR artifacts such as panhandle loops structures that can interfere with crossover detection (18). However, most crossover assays can be performed successfully without this step.

6. Tertiary PCR products can be typed for internal SNP markers in several ways, for example sequencing. Here, we describe a straightforward dotblot hybridization protocol that requires no specialist equipment. We type SNPs by hybridization of ASOs to dotblots of PCR products using a modification of the TMAC hybridization protocol 
((32)). TMAC allows oligonucleotides of differing GC content to be hybridized at the same temperature, greatly facilitating typing. Note that TMAC is toxic!

7. If you are labeling several ASOs, make a master mix of the kinase mix plus $\left[\gamma^{-32} \mathrm{P}\right]-\mathrm{ATP}$ plus T4 kinase, then aliquot $9 \mu \mathrm{L}$ per ASO and add the ASO to each aliquot.

8. If the ASO shows any lack of specificity, try re-washing for 20 min in TMAC wash solution at a higher temperature (e.g. $56^{\circ} \mathrm{C}$ or $60^{\circ} \mathrm{C}$ ) as in Section 3.3.3, steps 5-7.

9. Most ASOs are very specific, showing >100:1 discrimination between alleles. However, recombinant detection is limited by PCR mis-incorporations, which can arise in small DNA pools early during PCR to give artifact signals that can appear to be single site conversions. Different SNPs show different artifact levels, with transition SNPs (C/T, $\mathrm{A} / \mathrm{G})$ being most prone to switching by mis-incorporation. In practice, both misincorporation and ASO specificity mean that pool sizes have to be limited to 50 molecules at most, and preferably less. One 96-well plate will therefore allow at most only 4800 molecules to be screened for recombinants, limiting analysis to only the most active hotspots with recombination frequencies above $0.1 \%$.

\section{Acknowledgments}

Development of these methods was carried out at the University of Leicester with generous support by grants to A.J.J. from The Medical Research Council, The Louis-Jeantet Foundation and The Royal Society. L.K. was supported the Osk. Huttunen Foundation, the Finnish Cultural Foundation, the Instrumentarium Science Foundation and the Helsingin Sanomat Centennial Foundation. 


\section{References}

1. Cullen, M., Erlich, H., Klitz, W., and Carrington, M. (1995) Molecular mapping of a recombination hotspot located in the second intron of the human TAP2 locus. Am.J. Hum. Genet. 56, 1350-1358.

2. Cullen, M., Noble, J., Erlich, H., Thorpe, K., Beck, S., Klitz, W., et al. (1997) Characterization of recombination in the HLA class II region. Am. J. Hum. Genet. 60, 397-407.

3. Cruciani, F., Bernardini, L., Santolamazza, P., Modiano, D., Torroni, A., and Scozzari, R. (2003) Linkage disequilibrium analysis of the human adenosine deaminase (ada) gene provides evidence for a lack of correlation between hot spots of equal and unequal homologous recombination. Genomics 82, 20-33.

4. Smith, R. A., Ho, P. J., Clegg, J. B., Kidd, J. R., and Thein, S. L. (1998) Recombination breakpoints in the human beta-globin gene cluster. Blood 92, 4415-4421.

5. Twells, R. C., Mein, C. A., Phillips, M. S., Hess, J. F., Veijola, R., Gilbey, M., et al. (2003) Haplotype structure, LD blocks, and uneven recombination within the LRP5 gene. Genome Res. 13, 845-855.

6. Hedrick, P. W. (1987) Gametic disequilibrium measures: proceed with caution. Genetics 117, 331-341.

7. Ardlie, K. G., Kruglyak, L., and Seielstad, M. (2002) Patterns of linkage disequilibrium in the human genome. Nat. Rev. Genet. 3, 299-309.

8. Consortium, T. I. H. (2005) A haplotype map of the human genome. Nature 437, 12991320. 
9. Myers, S., Bottolo, L., Freeman, C., McVean, G., and Donnelly, P. (2005) A fine-scale map of recombination rates and hotspots across the human genome. Science 310, 321324.

10. Zavattari, P., Deidda, E., Whalen, M., Lampis, R., Mulargia, A., Loddo, M., et al. (2000) Major factors influencing linkage disequilibrium by analysis of different chromosome regions in distinct populations: demography, chromosome recombination frequency and selection. Hum. Mol. Genet. 9, 2947-2957.

11. Laan, M., and Paabo, S. (1997) Demographic history and linkage disequilibrium in human populations. Nat. Genet. 17, 435-438.

12. Tapper, W., Collins, A., Gibson, J., Maniatis, N., Ennis, S., and Morton, N. E. (2005) A map of the human genome in linkage disequilibrium units. Proc. Natl. Acad. Sci. USA 102, 11835-11839.

13. Crawford, D. C., Bhangale, T., Li, N., Hellenthal, G., Rieder, M. J., Nickerson, D. A., et al. (2004) Evidence for substantial fine-scale variation in recombination rates across the human genome. Nat. Genet. 36, 700-706.

14. Fearnhead, P., Harding, R. M., Schneider, J. A., Myers, S., and Donnelly, P. (2004) Application of coalescent methods to reveal fine-scale rate variation and recombination hotspots. Genetics 167, 2067-2081.

15. Jeffreys, A. J., Neumann, R., Panayi, M., Myers, S., and Donnelly, P. (2005) Human recombination hot spots hidden in regions of strong marker association. Nat. Genet. 37, 601-606. 
16. McVean, G. A., Myers, S. R., Hunt, S., Deloukas, P., Bentley, D. R., and Donnelly, P. (2004) The fine-scale structure of recombination rate variation in the human genome. Science 304, 581-584.

17. Jeffreys, A. J., Kauppi, L., and Neumann, R. (2001) Intensely punctate meiotic recombination in the class II region of the major histocompatibility complex. Nat. Genet. 29, 217-222.

18. Jeffreys, A. J., Murray, J., and Neumann, R. (1998) High-resolution mapping of crossovers in human sperm defines a minisatellite-associated recombination hotspot. Mol. Cell 2, 267-273.

19. Jeffreys, A. J., Ritchie, A., and Neumann, R. (2000) High resolution analysis of haplotype diversity and meiotic crossover in the human TAP2 recombination hotspot. Hum. Mol. Genet. 9, 725-733.

20. Kauppi, L., Stumpf, M. P., and Jeffreys, A. J. (2005) Localized breakdown in linkage disequilibrium does not always predict sperm crossover hot spots in the human MHC class II region. Genomics 86, 13-24.

21. May, C. A., Shone, A. C., Kalaydjieva, L., Sajantila, A., and Jeffreys, A. J. (2002) Crossover clustering and rapid decay of linkage disequilibrium in the $\mathrm{Xp} / \mathrm{Yp}$ pseudoautosomal gene SHOX. Nat. Genet. 31, 272-275.

22. Tiemann-Boege, I., Calabrese, P., Cochran, D. M., Sokol, R., and Arnheim, N. (2006) High-resolution recombination patterns in a region of human chromosome 21 measured by sperm typing. PLoS Genet. 2, e70. 
23. Jeffreys, A. J., Kauppi, L., and Neumann, R. (2001) Intensely punctate meiotic recombination in the class II region of the major histocompatibility complex. Nat. Genet. 29, 217-222.

24. Jeffreys, A. J., and May, C. A. (2003) DNA enrichment by allele-specific hybridization (DEASH): a novel method for haplotyping and for detecting low-frequency base substitutional variants and recombinant DNA molecules. Genome Res. 13, 2316-2324.

25. Jeffreys, A. J., and May, C. A. (2004) Intense and highly localized gene conversion activity in human meiotic crossover hot spots. Nat. Genet. 36, 151-156.

26. Holloway, K., Lawson, V. E., and Jeffreys, A. J. (2006) Allelic recombination and de novo deletions in sperm in the human beta-globin gene region. Hum. Mol. Genet.15, 1099-1111.

27. Jeffreys, A. J., and Neumann, R. (2005) Factors influencing recombination frequency and distribution in a human meiotic crossover hotspot. Hum. Mol. Genet. 14, 2277-2287.

28. Jeffreys, A. J., Tamaki, K., MacLeod, A., Monckton, D. G., Neil, D. L., and Armour, J. A. (1994) Complex gene conversion events in germline mutation at human minisatellites. Nat. Genet. 6, 136-145.

29. Cheng, S., Chang, S. Y., Gravitt, P., and Respess, R. (1994) Long PCR. Nature 369, 684685.

30. Dean, F. B., Hosono, S., Fang, L., Wu, X., Faruqi, A. F., Bray-Ward, P., et al. (2002) Comprehensive human genome amplification using multiple displacement amplification. Proc. Natl. Acad. Sci. USA 99, 5261-5266.

31. Jeffreys, A. J., and Neumann, R. (2002) Reciprocal crossover asymmetry and meiotic drive in a human recombination hot spot. Nat. Genet. 31, 267-271. 
32. Wood, W. I., Gitschier, J., Lasky, L. A., and Lawn, R. M. (1985) Base compositionindependent hybridization in tetramethylammonium chloride: a method for oligonucleotide screening of highly complex gene libraries. Proc. Natl. Acad. Sci. USA 82, 1585-1588. 


\section{Figure Legends}

Fig. 1. PCR approach for recovering crossover molecules directly from sperm DNA. (A) The first step is the discovery of single-nucleotide polymorphisms (SNPs, shown as grey circles) and LD mapping, allowing the identification of LD blocks (grey boxes) and regions where LD breaks down (gap between grey boxes). Such regions of LD breakdown are putative recombination hotspots. (B) For putative recombination hotspot regions, two rounds of allele-specific PCR are performed on batches of sperm DNA from an individual with multiple SNP heterozygosities (black and white circles). Allele-specific primers are shown as black and white arrowheads. Recombinant sperm DNA molecules are selectively amplified, and the location of crossover breakpoints can be subsequently mapped by typing internal SNPs.

Fig. 2. Principle of linkage phasing. Heterozygous selector SNPs are depicted as black and white circles, forward allele-specific primers (F1 and F2) and allele-specific reverse primers (R1 and R2) as black or white arrowheads. To determine the linkage phase of selector SNPs, PCR is performed using all four possible combinations of each allele-specific forward and reverse primer, in this example using F1-R2 combinations (rows 1-4).

Fig. 3. Schematic representation of crossover-positive secondary PCRs at input pool sizes of 2000, 600 and 200 DNA molecules, with eight PCRs per pool size. Here, eleven reactions (labelled 1-11) are positive for a crossover (e.g. 7/8 reactions at 2000 molecule input). The input pools shown would contain 2.08, 0.47 and 0.13 crossovers per reaction at 2000, 600 and 200 molecule input, respectively (see Section 3.2.4.4, step 1), giving approximate crossover frequencies of $1.0 \times 10^{-3}, 0.78 \times 10^{-3}$ and $0.65 \times 10^{-3}$ respectively. 
Fig. 4. Principle of crossover breakpoint mapping, (A) In the crossover assay, if forward primers are allele-specific for the A haplotype (black), and reverse primers for the B haplotype (white; allele-specific primers $A S$ ), "A to $\mathrm{B}$ " crossovers are amplified. Crossover-positive reactions and progenitor haplotypes $\mathrm{A}$ and $\mathrm{B}$ are re-amplified with universal primers (U). Five internal heterozygous SNP sites (numbered 3-7) and their inter-marker distances are shown. SNPs 1, 2, 8 and 9 are selector sites for allele-specific PCR. (B) Dotblot positions of progenitor haplotypes A and $\mathrm{B}$, plus the 11 hypothetical crossover positives from the different input pools (1-11) from Fig. 3 are shown. (C) Dotblots on the left are probed with ASOs targeted towards haplotype A alleles at heterozygous SNP sites (5' to 3', top to bottom: SNPs 3-7), while dotblots on the right are probed with ASOs specific for haplotype B. The haplotypic origin of each allele is identified from progenitor haplotype dots. Filled circles are positive for that particular haplotype, open dashed circles are negative (see Table 3A for crossover scoring). (D) Grey bars indicate recombination activity for each SNP interval (see Table 4A-B and Section 3.3.4. step 2 for calculations). The Poisson-corrected number of crossovers (rounded to nearest full number) observed in each interval is shown above each bar.

Fig. 5. Detecting crossovers and non-exchange gene conversions by the half-crossover assay. Multiple small pools (labeled A-D) of sperm DNA from a man carrying multiple SNP heterozygosities (white and black circles) are amplified by nested long PCR using allele-specific primers (white arrowheads) directed to white alleles plus universal primers (grey arrowheads). PCR products are then probed using ASOs specific to alleles from the unselected black haplotype. Various outcomes are possible in each pool. A, PCR products are derived only from 
white progenitor molecules. B, the pool contains a crossover in addition to progenitors, yielding a continuous block of positive markers distal to the selector sites. Note that any additional crossovers in this pool with exchange points mapping 3' to the observed crossover would not be detectable. $\mathrm{C}$, the pool contains a non-exchange gene conversion molecule, in this case affecting just one SNP. D, a complex pool containing two conversions and one crossover. The double-site conversion is masked by the crossover, and the single site conversion plus crossover appear as a single crossover with the exchange point mapping to the wrong interval. Pools B and D can be distinguished by further allele-specific PCR directed for example to the terminal SNP (marked with an asterisk), which allows crossovers and conversions to be separately amplified from nested PCR products prior to mapping.

Fig. 6. Principle of DEASH and subsequent detection of recombinants. (A) Digested doublestranded genomic DNA containing equal numbers of molecules differing by the chosen base substitution (circle) is mixed with a biotinylated ASO (bio-ASO, in black with biotin shown by a grey square) and the corresponding competitor ASO (white). The DNA is thermally denatured and the ASOs anneal as the temperature is subsequently reduced. Streptavidin-coated paramagnetic beads are then added, allowing the bio-ASO/target hybrid to be separated from the rest of the mixture with a magnet. The single-stranded target is released by thermal elution. The unbound fraction can be re-extracted by adding more bio-ASO, thus increasing the yield. Recovered fractions can be further enriched if additional bio-ASO and competitor ASO are added and the procedure repeated. (B) The recovered single-stranded DNA is greatly enriched for the selected haplotype (arrow indicates selector site, additional circles represent other SNP heterozygosities carried by this individual) (i). This facilitates detection of genuine recombinants 
exchanged at the selector site (a, crossover; $b$, gene conversion) using pools of the enriched DNA in a half-crossover assay (ii). Two-rounds of nested PCR are performed using allele-specific primers directed to the non-selected haplotype (white arrowheads) together with universal, i.e. non-allele specific, primers (grey arrowheads). Recombinants are detected by the presence of markers from the selected parental haplotype (black markers) as determined by ASO typing.

Fig. 7. Determining optimal yield and degree of purification post-DEASH. (A) Restricted DNA is enriched for molecules carrying the black allele (circle) using a biotinylated ASO as indicated by the arrow. Yield and purification are established by setting up two parallel sets of PCRs, one using an allele-specific primer directed against the selected haplotype (black triangle), the other using an allele-specific primer directed against the other haplotype (white triangle). The same reverse strand primer is used for both (grey triangle). Comparisons are made with the signals obtained from unfractionated DNA. (B) Hypothetical results from the DEASH eluates obtained using three different annealing temperatures $\left(\mathrm{A}_{1}{ }^{\circ} ; \mathrm{A}_{2}{ }^{\circ}, \mathrm{A}_{3}{ }^{\circ}\right)$ and three sequential elution temperatures (room temperature $[\mathrm{rt}], 60^{\circ} \mathrm{C}, 70^{\circ} \mathrm{C}$ ). Regardless of annealing temperature, little target is released either at the rt or $70^{\circ} \mathrm{C}$ elution steps; the majority of DNA can be recovered by simply raising the elution temperature to $60^{\circ} \mathrm{C}$. The yield of selected haplotype is determined as $\sim 75 \%, \sim 50 \%$ and $\sim 3 \%$ for annealing temperatures $\mathrm{A}_{1}{ }^{\circ}, \mathrm{A}_{2}{ }^{\circ}, \mathrm{A}_{3}{ }^{\circ}$ respectively. The degree of purification is determined from the non-selected haplotype PCRs; for example, for $\mathrm{A}_{2}{ }^{\circ}$, the signal is approximately equivalent to that from the $0.5 \%$ input control, such that fraction is enriched 100 fold $(=50 / 0.5)$ for the selected haplotype. This degree of purification appears better than that obtained at $\mathrm{A}_{1}{ }^{\circ}(12.5$ fold [75/6]), so bulk fractionation would best be carried out at $\mathrm{A}_{2}{ }^{\circ}$. 
Table 1. Recipe for 11.1x PCR buffer.

\begin{tabular}{cccc}
\hline Component & $\begin{array}{c}\text { Concentration of } \\
\text { Stock Solution }\end{array}$ & $\begin{array}{c}\text { Volume } \\
\text { (arbitrary units) }\end{array}$ & $\begin{array}{c}\text { Final Concentration } \\
\text { in PCR }\end{array}$ \\
\hline Tris-HCl pH 8.8 & $2 \mathrm{M}$ & 167 & $45 \mathrm{mM}$ \\
ammonium sulphate & $1 \mathrm{M}$ & 83 & $11 \mathrm{mM}$ \\
MgCl2 & $1 \mathrm{M}$ & 33.5 & $4.5 \mathrm{mM}$ \\
2-mercaptoethanol & $100 \%$ & 3.6 & $6.7 \mathrm{mM}$ \\
EDTA pH 8.0 & $10 \mathrm{mM}$ & 3.4 & $4.4 \mu \mathrm{M}$ \\
dATP & $100 \mathrm{mM}$ & 75 & $1 \mathrm{mM}$ \\
dCTP & $100 \mathrm{mM}$ & 75 & $1 \mathrm{mM}$ \\
dGTP & $100 \mathrm{mM}$ & 75 & $1 \mathrm{mM}$ \\
dTTP & $100 \mathrm{mM}$ & 75 & $113 \mu \mathrm{g} / \mathrm{ml}$ \\
BSA & $10 \mathrm{mg} / \mathrm{ml}$ & 85 & \\
\hline Total Volume & & 676 & \\
\hline & & & \\
\hline
\end{tabular}

20. Kauppi et al. 
Table 2. Examples of allele-specific PCR primers used in crossover assays. Bases in lowercase are 5' extensions used to boost GC content, not part of the genomic sequence.

$\begin{array}{llll}\text { Primer name } & \mathbf{5}^{\prime} \text { to } \mathbf{3}^{\prime} \text { sequence } & \text { length } & \text { \%GC } \\ \text { F7R2G } & \text { GTGGGCCCCAGGAC } & 14 & 79 \\ \text { BC4RC } & \text { GAGGAAAGCTGGGGGTAG } & 18 & 61 \\ \text { A7FG } & \text { CGTCCACTGGAAACGTTG } & 18 & 56 \\ \text { B7RT/Ad } & \text { gtctacgtagtcagctctgGAAATGGTCAAATTTTATGTA } & 21+\text { Ad } & 38 \\ \text { B7RG/Ad } & \text { gtctacgtagtcagctctgGAAATGGTCAAATTTTATGTC } & 21+\text { Ad } & 40 \\ \text { JJ6FT2 } & \text { GCTCTGGTGGTGTGGT } & 16 & 63 \\ \text { JJ6FC } & \text { CTGCTCTGGTGGTGTGGC } & 18 & 67 \\ \text { J7RC } & \text { GCCTAAGAGCAGAGGGAG } & 18 & 61 \\ \text { J7RT } & \text { GCCTAAGAGCAGAGGGAA } & 18 & 56 \\ \text { JJ7FA1 } & \text { ccccCTTGCTTTGAAATGAGGA } & 18+c c c c & 50 \\ \text { JJ7FC2 } & \text { cccCTTGCTTTGAAATGAGGC } & 18+c c c c & 55\end{array}$


Table 3. Example of crossover scoring. (A) In the crossover assay example given in Fig. 3, eight pools of 2000, 600 and 200 amplifiable molecules each were screened (24 PCRs, 22,400 molecules in total). Eleven of the 24 PCRs were positive for crossovers (dots 1-11 on blot in Fig. 4B, and rows 1-11 in this table). Progenitor haplotypes A and B (black and white) are indicated at top. The status of heterozygous SNPs is shown for each crossover-positive PCR. Five (dots 14 and 6 in Fig. 4C) of the eleven positive reactions contain two or more different crossovers as shown by mixed SNP sites (M). (B) Resolution of crossover mixtures. For example, reaction 1 is resolved as $1 \mathrm{a}$ and $1 \mathrm{~b}$ (see Section 3.3.4). Note that dot 1 could contain an undetectable crossover between SNP4 and SNP5 and/or between SNP5 and SNP6. (C) Crossovers ordered according to breakpoint location, $5^{\prime}$ to $3^{\prime}$, and numbers of crossovers per SNP interval. The single crossover observed in the 5 ' end interval is shown in parentheses. 


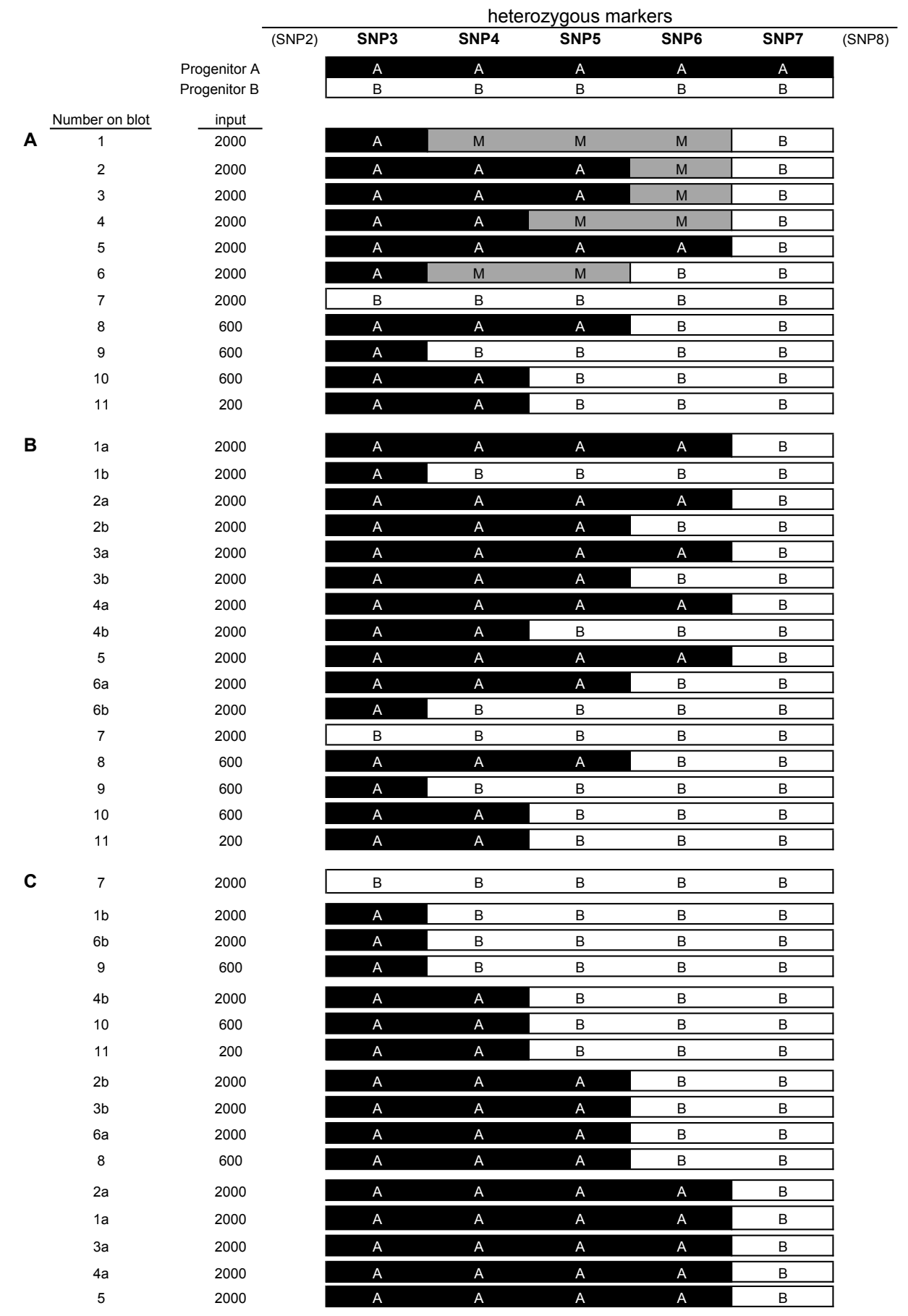


Table 4. Calculating crossover frequencies for each SNP interval. (A) Total number of positive plus negative reactions for each input pool, per SNP interval. Crossover-positive pools that contain crossover mixtures spanning more than one interval (in grey italics) are excluded for all SNP sites that lie between the two SNP intervals where crossover breakpoints were scored. For example, crossover 6 is excluded for the SNP4-SNP5 interval. The total number of molecules screened is lower for the SNP4-SNP5 and SNP5-SNP6 intervals (open box), as follows: 22,400 $(2 \times 2000)=18,400$, because two of the 2000-molecule input pools are excluded for these intervals. (B) The Poisson-corrected number of crossovers in each interval is determined, and if necessary adjusted upwards to take into account any PCRs in which mixed sites make crossover detection impossible. Thus the Poisson-corrected number of crossovers in interval SNP4-SNP5 is adjusted by the factor $22,400 / 18,400$. Recombination activity per interval then is calculated from the corrected number of crossovers and inter-marker distance. End interval crossovers (in parentheses) are scored as normal but we exclude them from further analyses if they are likely to result from parental haplotype bleed-through amplification (see Section 3.3.4).

A

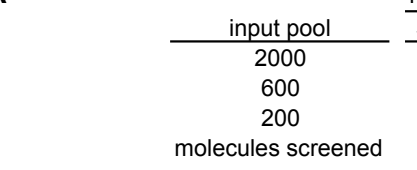

molecules screened

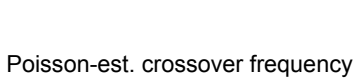

B

uncorrected number of crossovers Poisson-corr. number of crossovers inter-marker distance (bp) $\mathrm{cM} / \mathrm{Mb}$ number of crossover positive + negative reactions for each SNP interval, in each input pool \begin{tabular}{lllll} 
SNP2 to SNP3 SNP3 to SNP4 & SNP4 to SNP5 & SNP5 to SNP6 & SNP6 to SNP7 & SNP7 to SNP8 \\
\hline
\end{tabular}

$\begin{array}{llllll}1+7 & 2+6 & 1+5 & 3+3 & 5+3 & 0+8\end{array}$
$\begin{array}{ll}1+7 & 2+6 \\ 0+8 & 1+7\end{array}$ $\begin{array}{cc}0+8 & 0+8 \\ 22400 & 22400\end{array}$

$1+7$

$\begin{array}{llll}1+7 & 0+8 & 0+8 & 0+8\end{array}$

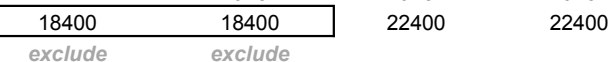

crossover positives crossover positives

1 and $6 \quad 1$ and 4

\begin{tabular}{|c|c|c|c|c|c|c|}
\hline- & 0.00015 & 0.00018 & 0.00027 & 0.00030 & - & \\
\hline SNP2 to SNP3 & SNP3 to SNP4 & SNP4 to SNP5 & SNP5 to SNP6 & SNP6 to SNP7 & SNP7 to SNP8 & \\
\hline (1) & 3 & 3 & 4 & 5 & 0 & total: 16 \\
\hline 0 & 3.4 & 3.3 & 5.0 & 6.7 & 0 & total: 19.4 \\
\hline 1000 & 500 & 250 & 250 & 500 & 1500 & \\
\hline (4.5) & 30 & 72 & 108 & 60 & 0 & \\
\hline
\end{tabular}


Table 5. Examples of biotinylated ASOs used in DEASH experiments to recover gene conversion events. Indel, insertion/deletion; Ti, transition; Tv, transversion. SNP variants are shown in bold, and the insertion site for the + variant of the indel is shown in bold italics.

$\begin{array}{lllllll}\begin{array}{l}\text { SNP type } \\ \text { (variants) }\end{array} & \text { Bio-ASO }\left(\mathbf{5}^{\prime} \text { to 3') }\right. & \text { \%GC } & \mathbf{A}^{\circ} & \begin{array}{c}\text { target } \\ (\mathbf{k b})\end{array} & \text { \%yield } & \text { purification } \\ & & & & & & \\ \text { Indel (-/AGA) } & \text { Bio-GAAAAAAAGAGGAGTGGA } & 39 & 49 & 6.6 & 60 & 7 \mathrm{x} \\ \operatorname{Ti}(\mathrm{C} / \mathrm{T}) & \text { Bio-AAAAGGAGTGCGTGTGTG } & 50 & 50 & 6.6 & 60 & 13 \mathrm{x} \\ \mathrm{Tv}(\mathrm{G} / \mathrm{C}) & \text { Bio-AATAGGGAGAGGATAAAG } & 39 & 42 & 10.2 & 60 & 100 \mathrm{x} \\ \mathrm{Ti}(\mathrm{A} / \mathrm{G}) & \text { Bio-GGTGAGAGGAAAGAAGTG } & 50 & 45 & 6.6 & 65 & 120 \mathrm{x} \\ \mathrm{Tv}(\mathrm{C} / \mathrm{G}) & \text { Bio-AATAGGGAGACGATAAAG } & 39 & 42 & 12.5 & 20 & 200 \mathrm{x} \\ \mathrm{Tv}(\mathrm{G} / \mathrm{C}) & \text { Bio-GGACGGGCTGGGGTTCCT } & 72 & 55 & 9.4 & 30 & >200 \mathrm{x} \\ \mathrm{Ti}(\mathrm{C} / \mathrm{T}) & \text { Bio-ACTAATGATTCACTAACA } & 28 & 40 & 7.0 & 45 & 300 \mathrm{x} \\ \mathrm{Tv}(\mathrm{T} / \mathrm{G}) & \text { Bio-GTTTGTTGTTTTTTGTTT } & 22 & 35 & 7.0 & 45 & >300 \mathrm{x}\end{array}$


target region

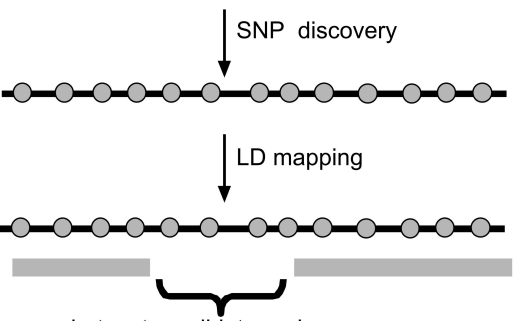

hotspot candidate region

B. Crossover analysis

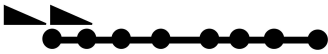

$\mathrm{O}-\mathrm{O}=\mathrm{O}-\mathrm{O}-\mathrm{O}=\mathrm{O}=\mathrm{O}$

$\downarrow$ allele-specific PCR

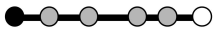

$\downarrow$ crossover breakpoint mapping
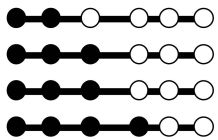

$\mathrm{C}-\mathrm{O}=\mathrm{O}=\mathrm{O}=\mathrm{O}$ 
F1 F2

R2 R1

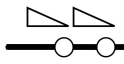

PCR product?

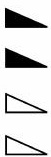

4

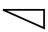

$\longrightarrow$

$\longrightarrow$
난

-

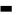

ש 
$8 \times 2,000$

\begin{tabular}{|lllllll|lll|l|}
\hline & 2 & 3 & 4 & 5 & 6 & 7 & 8 & 9 & 10 & 11 \\
\hline
\end{tabular}

total number of molecules: 22,400 
$D \quad *$

000000000000

000000000

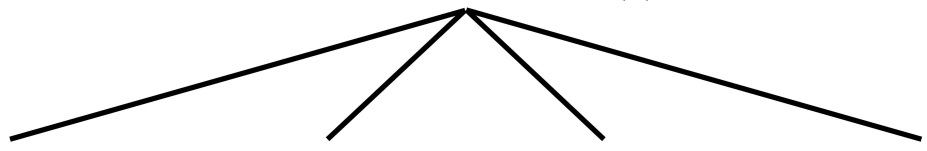

A

B

C

D

O0000000000$00000000000-$ 000000000000000000000000000000000$00000000000-$ $00000000000-$
0000000000000000000000ం,000000000000000000000000000000$00000000000-$ 00000000000-
00000000000 $00000000000-$ 0000-00000000000000000000000000000000000000000000000000-
$00000000000-$ 0,00-0000000,0000000000, ం-000000000ం-00000000000000

$----+++++++$

$-\ldots+\ldots+\ldots$

$---+++++++$ 
A.

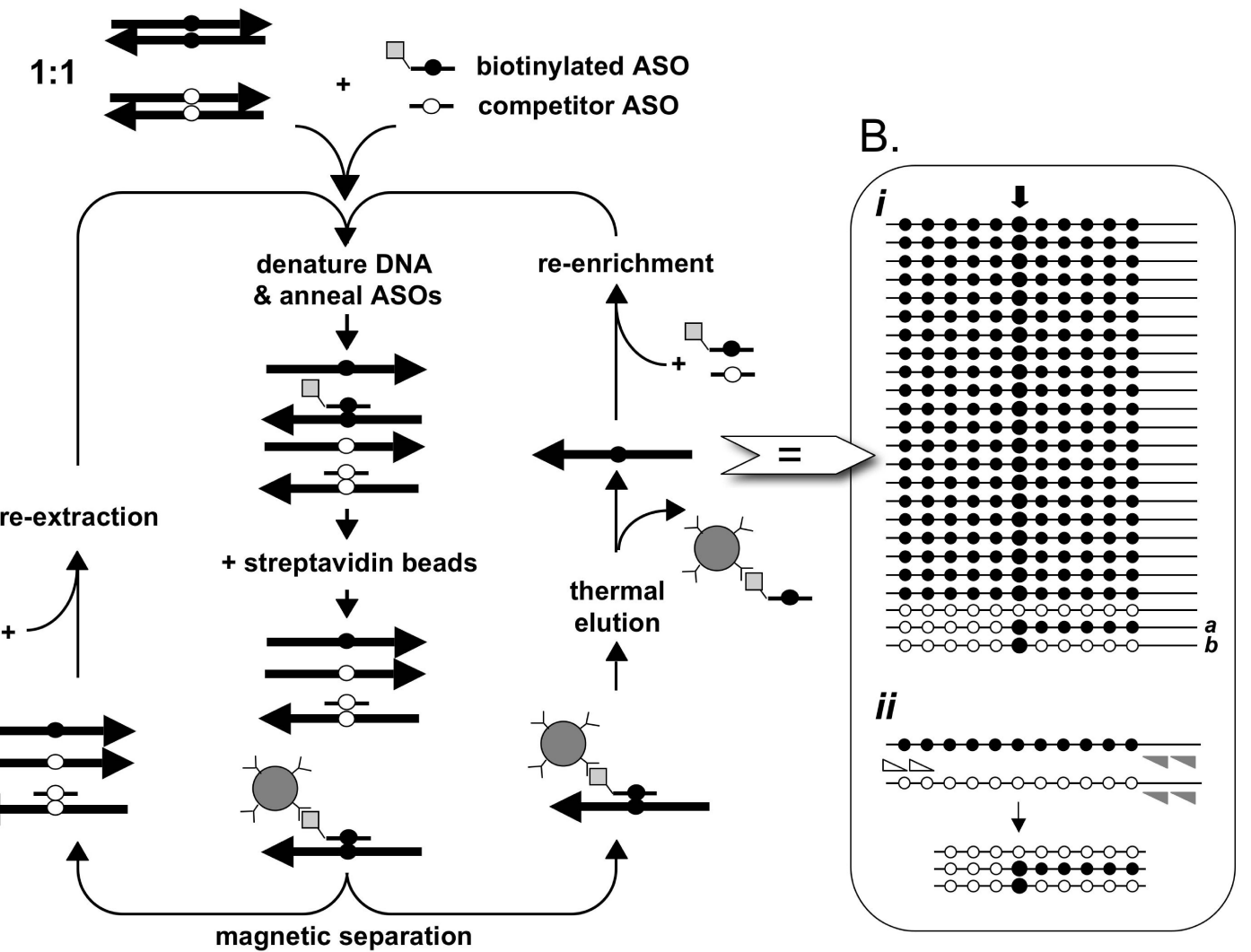


A.

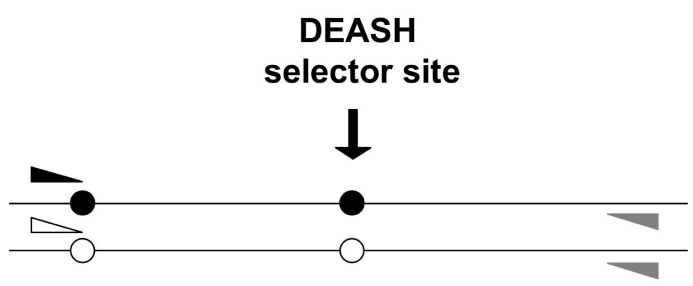

B.

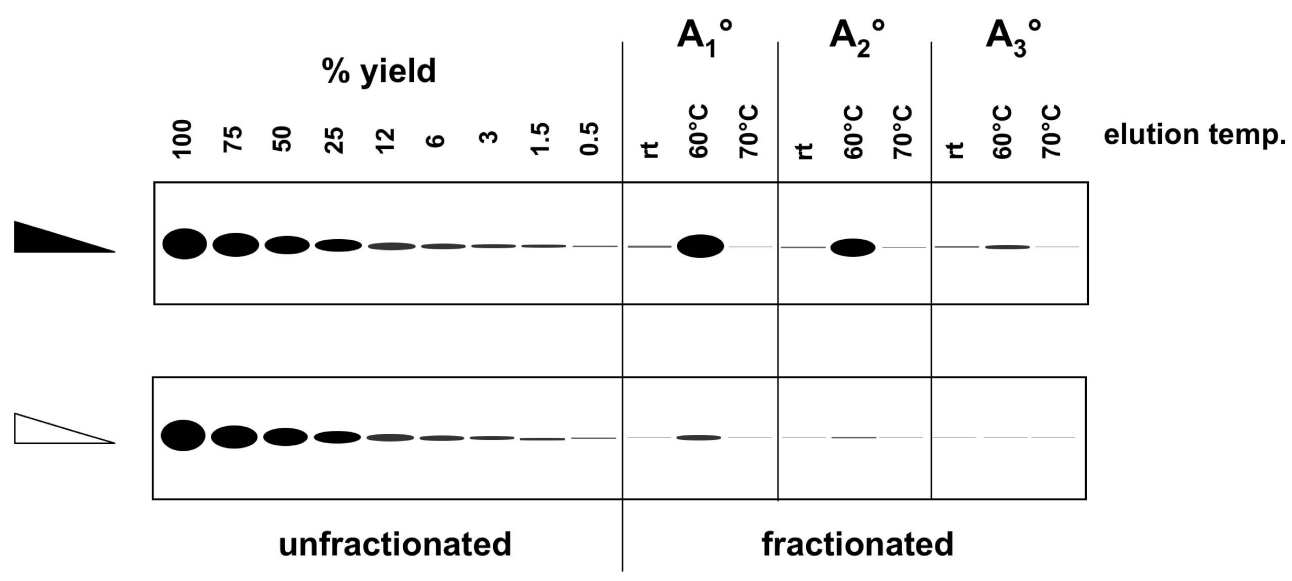

